\title{
Atherothrombosis and Thromboembolism: Position Paper from the Second Maastricht Consensus Conference on Thrombosis
}
H. M. H. Spronk ${ }^{1}$
T. Padro ${ }^{2}$
J. E. Siland ${ }^{3}$
J. H. Prochaska 4
J. Winters ${ }^{5}$
A. C. van der Wal ${ }^{6}$
J. J. Posthuma ${ }^{1}$
G. Lowe ${ }^{7}$
E. d'Alessandro 5,6
P. Wenzel ${ }^{8}$
D. M. Coenen ${ }^{9}$
P. H. Reitsma ${ }^{10}$
W. Ruf 4
R. H. van Gorp 9
R. R. Koenen ${ }^{9}$
T. Vajen ${ }^{9}$
N. A. Alshaikh ${ }^{9}$
A. S. Wolberg ${ }^{11}$
F. L. Macrae ${ }^{12}$
N. Asquith ${ }^{12}$ J. $H^{2}$
J. C. M. Meijers
Heemskerk $^{9}$
A. Heinzmann ${ }^{9}$
M. Moorlag ${ }^{13}$
N. Mackman ${ }^{14}$
P. van der Meijden ${ }^{9}$
J. C. M. Meijers
C. C. Baaten
M. Heestermans ${ }^{10}$
T. Renné ${ }^{16,17}$
S. Dólleman ${ }^{18}$
W. Chayouâ ${ }^{13}$
R. A. S. Ariëns ${ }^{12}$
E. A. M. P. Dudink ${ }^{21}$
A. Kuliopulos ${ }^{19}$
J. J. Posma ${ }^{1}$
P. Harrison 20
M. J. Vries ${ }^{1}$
H. J. G. M. Crijns ${ }^{21}$
J. W. Eikelboom 24
H. R. Buller 22
Y. M.C. Henskens ${ }^{1}$
A. Själander ${ }^{23}$
S. Zwaveling ${ }^{1,13}$
O. Erküner ${ }^{21}$
U. Schotten ${ }^{4}$
B. Scaf ${ }^{1,5}$
A. Gulpen ${ }^{1}$
F. E. C. M. Peeters ${ }^{21}$
J. Douxfils ${ }^{25}$
R. H. Olie ${ }^{1}$
T. Baglin 26
A. Leader ${ }^{1,27}$
M. Visser ${ }^{31}$
D. W. J. Dippel ${ }^{32}$
V. J. Strijbis ${ }^{13}$
K. Pertiwi ${ }^{33}$
A. J. ten Cate-Hoek ${ }^{1}$
P. Declerck ${ }^{30}$

${ }^{1}$ Laboratory for Clinical Thrombosis and Haemostasis,

Cardiovascular Research Institute Maastricht (CARIM), Maastricht

University Medical Center, Maastricht, The Netherlands

${ }^{2}$ Cardiovascular Research Center (ICCC), Hospital Sant Pau,

Barcelona, Spain

${ }^{3}$ Department of Cardiology, University Medical Center Groningen,

Groningen, The Netherlands

${ }^{4}$ Center for Cardiology/Center for Thrombosis and Hemostasis/

DZHK, University Medical Center of the Johannes Gutenberg

University Mainz, Mainz, Germany

${ }^{5}$ Department of Physiology, Cardiovascular Research Institute Maastricht (CARIM), Maastricht University, Maastricht, The Netherlands

6 Department of Pathology, Academic Medical Center (AMC), Amsterdam, The Netherlands

${ }^{7}$ Institute of Cardiovascular and Medical Sciences, University of Glasgow, Glasgow, Scotland

8 Department of Cardiology, Universitätsmedizin Mainz, Mainz, Germany

${ }^{9}$ Department of Biochemistry, Cardiovascular Research Institute Maastricht (CARIM), Maastricht University, Maastricht, The Netherlands

10 Einthoven Laboratory, Leiden University Medical Center, Leiden, The Netherlands

${ }^{11}$ Department of Pathology and Laboratory Medicine, University of North Carolina, Chapel Hill, North Carolina, United States

12 Thrombosis and Tissue Repair Group, Division of Cardiovascular and Diabetes Research, Leeds Institute of Cardiovascular and Metabolic Medicine, School of Medicine, University of Leeds, Leeds, UK

13 Synapse, Maastricht, The Netherlands

${ }^{14}$ Department of Medicine, UNC McAllister Heart Institute, University of North Carolina, Chapel Hill, North Carolina, United States

${ }^{15}$ Department of Plasma Proteins, Sanquin, Amsterdam, The Netherlands

${ }^{16}$ Department of Molecular Medicine and Surgery, Karolinska Institutet and University Hospital, Stockholm, Sweden,

Thromb Haemost 2018;118:229-250.
${ }^{17}$ Institute of Clinical Chemistry and Laboratory Medicine, University Medical Center Hamburg-Eppendorf, Hamburg, Germany

18 Department of Nephrology, Leiden University Medical Centre, Leiden, The Netherlands

${ }^{19}$ Tufts University School of Graduate Biomedical Sciences, Biochemistry/Developmental, Molecular and Chemical Biology, Tufts University School of Medicine, Boston, Massachusetts

20 Institute of Inflammation and Ageing, University of Birmingham, Birmingham, United Kingdom

${ }^{21}$ Department of Cardiology, Cardiovascular Research Institute Maastricht (CARIM), Maastricht University Medical Center, Maastricht, The Netherlands

${ }^{22}$ Department of Vascular Medicine, Academic Medical Center (AMC), Amsterdam, The Netherlands

${ }^{23}$ Department of Public Health and Clinical Medicine, Umeå University, Umeå, Sweden

${ }^{24}$ Department of Medicine, McMaster University, Hamilton, Ontario, Canada

${ }^{25}$ Department of Pharmacy, Thrombosis and Hemostasis Center, Faculty of Medicine, Namur University, Namur, Belgium

${ }^{26}$ Department of Haematology, Addenbrookes Hospital Cambridge, Cambridge, United Kingdom

27 Davidoff Cancer Center, Rabin Medical Center, Institute of Hematology, Sackler Faculty of Medicine, Tel Aviv University, Petah Tikva, Tel Aviv, Israel

${ }^{28}$ Department of Experimental Cardiology, Erasmus Medical Center, Rotterdam, The Netherlands

29 Department of Molecular and Experimental Medicine, The Scripps Research Institute, La Jolla, United States

${ }^{30}$ Department of Pharmaceutical and Pharmacological Sciences, University of Leuven, Leuven, Belgium

${ }^{31}$ Bayer AG, Wuppertal, Germany

${ }^{32}$ Department of Neurology, Erasmus MC, Rotterdam, The Netherlands

33 Department of Cardiovascular Pathology, University of Amsterdam, Academic Medical Center, Amsterdam, The Netherlands received

July 20, 2017

accepted after revision

October 30, 2017
Copyright ๑ 2018 Schattauer

DOI https://doi.org/ 10.1160/TH17-07-0492. ISSN 0340-6245. 
Address for correspondence Hugo ten Cate, MD, PhD, Laboratory for Clinical Thrombosis and Haemostasis, Cardiovascular Research Institute Maastricht (CARIM), Maastricht University, P.O. Box 616, UNS50: Box 8, 6200 MD Maastricht, The Netherlands (e-mail: h.tencate@maastrichtuniversity.nl).

\section{Abstract}

\section{Keywords}

- atherothrombosis

- arterial thrombosis

- coagulation

- platelets

- antiplatelet therapy

- anticoagulants

- atherosclerosis

- ischaemic stroke

- atrial fibrillation

- myocardial infarction
Atherothrombosis is a leading cause of cardiovascular mortality and long-term morbidity. Platelets and coagulation proteases, interacting with circulating cells and in different vascular beds, modify several complex pathologies including atherosclerosis. In the second Maastricht Consensus Conference on Thrombosis, this theme was addressed by diverse scientists from bench to bedside. All presentations were discussed with audience members and the results of these discussions were incorporated in the final document that presents a state-of-the-art reflection of expert opinions and consensus recommendations regarding the following five topics:

1. Risk factors, biomarkers and plaque instability: In atherothrombosis research, more focus on the contribution of specific risk factors like ectopic fat needs to be considered; definitions of atherothrombosis are important distinguishing different phases of disease, including plaque (in)stability; proteomic and metabolomics data are to be added to genetic information.

2. Circulating cells including platelets and atherothrombosis: Mechanisms of leukocyte and macrophage plasticity, migration, and transformation in murine atherosclerosis need to be considered; disease mechanism-based biomarkers need to be identified; experimental systems are needed that incorporate whole-blood flow to understand how red blood cells influence thrombus formation and stability; knowledge on platelet heterogeneity and priming conditions needs to be translated toward the in vivo situation.

3. Coagulation proteases, fibrin(ogen) and thrombus formation: The role of factor (F) XI in thrombosis including the lower margins of this factor related to safe and effective antithrombotic therapy needs to be established; FXI is a key regulator in linking platelets, thrombin generation, and inflammatory mechanisms in a renin-angiotensin dependent manner; however, the impact on thrombin-dependent PAR signaling needs further study; the fundamental mechanisms in FXIII biology and biochemistry and its impact on thrombus biophysical characteristics need to be explored; the interactions of red cells and fibrin formation and its consequences for thrombus formation and lysis need to be addressed. Platelet-fibrin interactions are pivotal determinants of clot formation and stability with potential therapeutic consequences.

4. Preventive and acute treatment of atherothrombosis and arterial embolism; novel ways and tailoring? The role of protease-activated receptor (PAR)- 4 vis à vis PAR- 1 as target for antithrombotic therapy merits study; ongoing trials on platelet function test-based antiplatelet therapy adjustment support development of practically feasible tests; risk scores for patients with atrial fibrillation need refinement, taking new biomarkers including coagulation into account; risk scores that consider organ system differences in bleeding may have added value; all forms of oral anticoagulant treatment require better organization, including education and emergency access; laboratory testing still needs rapidly available sensitive tests with short turnaround time.

5. Pleiotropy of coagulation proteases, thrombus resolution and ischaemia-reperfusion: Biobanks specifically for thrombus storage and analysis are needed; further studies on novel modified activated protein C-based agents are required including its cytoprotective properties; new avenues for optimizing treatment of patients with ischaemic stroke are needed, also including novel agents that modify fibrinolytic activity (aimed at plasminogen activator inhibitor-1 and thrombin activatable fibrinolysis inhibitor. 


\section{Introduction}

During the second Maastricht Consensus Conference on Thrombosis (MCCT), atherothrombosis and cardiovascular disease (CVD) were tackled from different angles by basic and clinical scientists, younger as well as seasoned experts from an international background. Concise presentations on subtopics within a larger theme (www.mcct.eu) were held, followed by discussion sessions (presenters, students, other attendants) to outline targets for future research. Based on a plenary synthesis of all sessions, a final consensus document

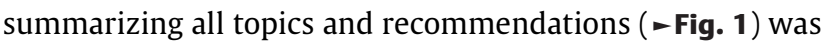
drafted based on the notes from all contributing authors and condensed into this position paper. This document does not intend to provide a comprehensive overview of the field; primarily it reflects the personal interests and opinions of the experts and input from the audience.

\section{Risk Factors, Biomarkers and Plaque Instability}

Atherothrombosis occurs in the course of atherosclerosis, a condition driven by chronic inflammation. ${ }^{1,2}$ Current concepts on 'thomboinflammation' 3 also fit in the context of atherothrombosis driven by the interplay between inflammation and coagulation as a critical mechanism., ${ }^{4,5}$ Obesity is one of the main drivers of chronic inflammation in atherogenesis.

\section{Obesity, Ectopic Fat and Thromboinflammation}

Obesity is a worldwide health problem with increasing prevalence. ${ }^{6}$ Although obesity is heterogeneous, approximately $30 \%$ of obese individuals remain healthy into old age. ${ }^{7}$ Ectopic fat accumulation rather than overall obesity is responsible for increased cardiometabolic risk and is a better predictor for CVD, including atrial fibrillation (AF) and heart failure. ${ }^{8-10}$ Ectopic fat refers to fat that accumulates in or around specific organs or compartments and include abdominal viscera (visceral fat), liver (intrahepatic fat), heart (pericardial fat), and blood vessels (perivascular fat). Recent findings support an independent contribution of ectopic fat deposition to cardiovascular risk. ${ }^{11}$

Strengthening research on the contribution of ectopic fat depots to cardiometabolic risk and risk of CVD is necessary. Adipose tissue is a dynamic endocrine organ consisting of adipocytes and nonadipocytes including immune cells. Excess ectopic fat may exert harmful effects by direct lipotoxicity, or by a chronic proinflammatory effect, at both the local and systemic level. The impact of ectopic fat on CVD might occur at different stages of disease progression. The growth of fat mass leads to changes in the adipocyte cell size and number as well as in the pattern of immune cells with an exacerbated presence of macrophages and lymphocytes, with a proinflammatory phenotype. This leads to a deregulated expression of bioactive molecules including cytokines and adipokines, which contribute to inflammation, endothelium dysfunction, progression of atherogenesis, and a prothrombotic state, all increasing cardiovascular risk. ${ }^{12,13}$ Further research should unravel differences between fat depots in cell composition, inflammatory response, and cell-signaling pathways and ultimately how this translates into atherosclerosis.

Traditionally, obesity is determined through the body mass index (BMI), but clearly, the pattern of fat distribution is more important than the absolute amount of stored fat; it is conceivable that ectopic fat becomes the diagnostic and therapeutic target in cardiometabolic disorders shifting the

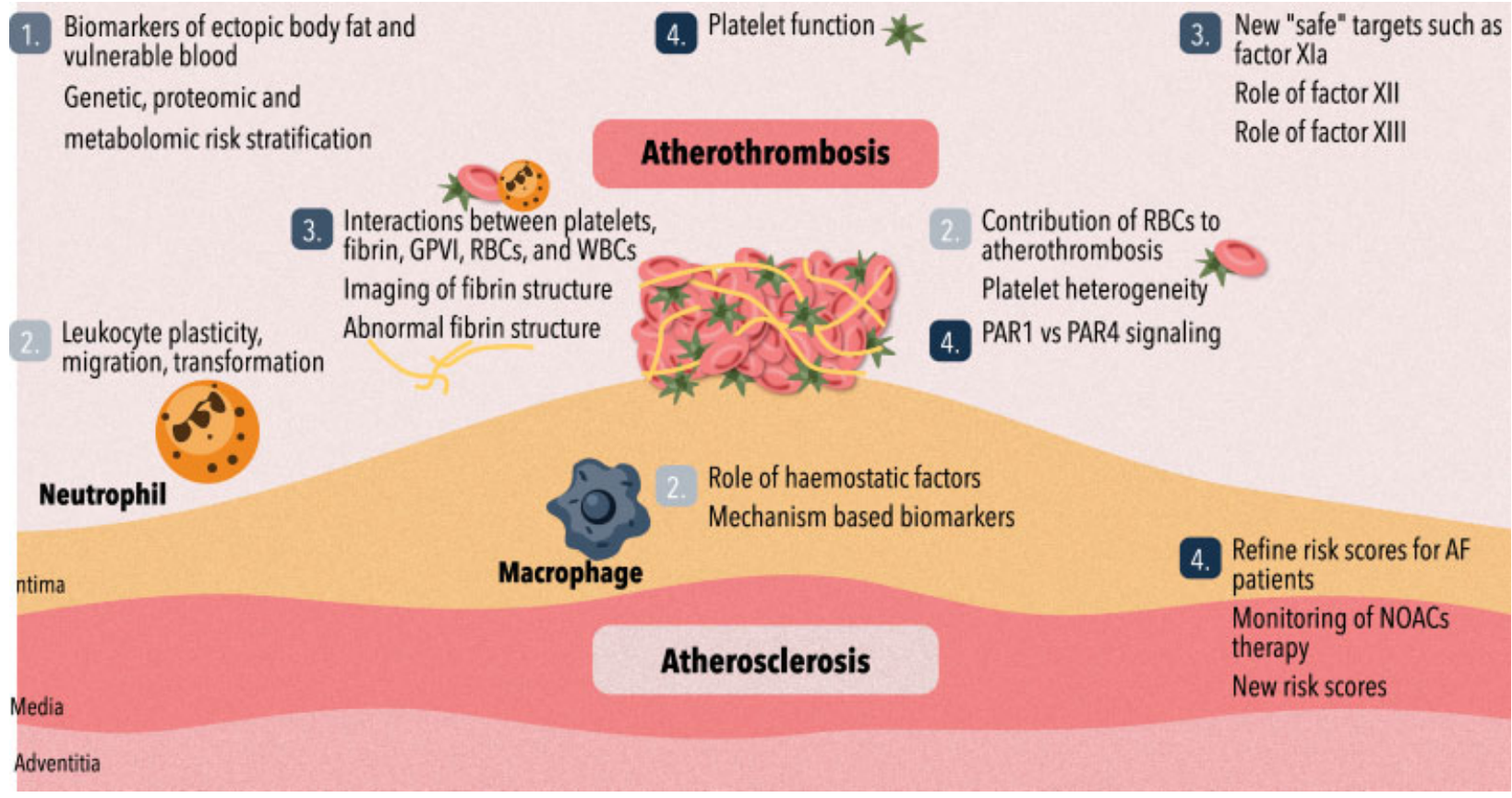

Fig. 1 Visual representation of the consensus recommendations regarding (1) risk factors, biomarkers and plaque instability; (2) circulating cells including platelets and atherothrombosis; (3) coagulation proteases, fibrin(ogen) and thrombus formation; and (4) preventive and acute treatment of atherothrombosis and arterial embolism; novel ways and tailoring? 
focus from quantity (obesity) to quality (dysfunctional fat). ${ }^{14}$ Current methodologies for tracking ectopic fat distribution are limited to expensive imaging techniques (e.g. computed tomography [CT], magnetic resonance imaging [MRI]). ${ }^{15}$

\section{Genetics and Cardiovascular Disease}

For the advancement of prevention in CVD, improving the accuracy of genetic risk stratification will be of major importance. Single nucleotide polymorphisms increasing the risk of CVD via interference with inflammation, lipids, blood pressure, nitric oxide/cyclic guanosine monophosphate signaling, vascular remodelling, and plaque formation have been detected. ${ }^{16}$ Several research groups have addressed the implementation of these genetic variants into genetic risk models for arterial thrombosis. ${ }^{17,18}$ Nevertheless, current guidelines recommend only standardized assessment of family history of premature CVD and discourage the generalized use of DNA-based test for risk assessment. ${ }^{19}$ Since current treatment concepts predominantly focus on the therapy of disease phenotypes and our understanding of organ-specific gene translation is still limited, more efforts are needed to unravel gene-gene and gene-environment interactions in a systems-medicine-oriented approach.

To improve current knowledge about the translation of genotype into phenotype, integrative data analysis and deep clinical phenotyping for subclinical disease will be required. Therefore, epigenetic, proteomic, and metabolomic information should be analysed in conjunction with genomic data to improve the understanding of the pathophysiology of CVD and to advance the prevention of CVD. Considering the required sample size and the expertise in 'omics-technology' and bioinformatics needed to study the complex interplay of genetic variation and its functional role, combined efforts (e.g. in consortia) will be needed. These efforts should be accompanied by an interdisciplinary discussion on ethical aspects, as advancements in the field of genetics will entail novel ethical demands for regulatory authorities, health care providers and patients.

\section{Phenotyping the Atherothrombotic Lesion}

Tissue composition of plaques rather than the degree of luminal stenosis determines the vulnerability of an atherosclerotic plaque to develop disruption followed by thrombosis. ${ }^{20}$ A thin fibrous cap, large lipid-rich necrotic core, low amount of collagen, and high inflammatory activity are major determinants of plaque vulnerability. ${ }^{2,21}$ Tissue characteristics of high-risk plaques can now be visualized with the use of invasive vascular imaging techniques, which has created considerable progress in defining the composition of plaques in patients. Intravascular ultrasound with virtual histology analysis provides a cross-section view of the entire vessel wall and allows to detect the thickness of a fibrous cap and size of a lipid core. $^{22}$ Optical coherence tomography (OCT) provides higher resolution imaging but limited depth penetrance, with more detailed information on the near lumen morphology such as fibrous cap structure, superficial macrophage accumulations, or plaque rupture. ${ }^{23}$ However, imaging of the activity and specific location of inflammatory cells and their secretory products in plaques is less succesful. ${ }^{24}$ Some progress has been made in experimental settings. For example, a critical step in the destabilization of plaques is the secretion of matrixdegrading metalloproteinases (MMPs) by inflammatory cells. ${ }^{25}$ With the use of single-photon emission computed tomography/micro-CT imaging with radiolabelled metalloproteinase inhibitors, MMP activity could be detected in animals (rabbits) in a noninvasive manner. ${ }^{26}$ And in humans, application of near-infrared autofluorescence imaging appeared successful in detecting fluorescence of naturally occurring molecules in necrotic cores of high-risk plaques, which provides some information about the biological activity inside a lesion. ${ }^{27}$ Such noninvasive imaging techniques describing plaque phenotype over time could elucidate the relation between inflammation, plaque vulnerability, and clinical events. Still, up to now it remains a challenge to predict plaque rupture in individual patients. ${ }^{28}$ Therefore, there is a call for new definitions and risk assessment strategies regarding atherothrombosis. Besides morphology of plaques, vulnerability of blood (e.g. hypercoagulability and inflammation) is a contributor to atherothrombosis. $^{28}$

There is a knowledge gap with respect to biomarkers of ongoing plaque destabilization. Pathologic analysis of thrombectomy specimens retrieved from acute myocardial infarction (AMI) patients has revealed huge variations in the propagation of thrombosis after onset of plaque rupture. Stratification of the so-called fresh ( $<1$ day) and old ( $>5$ days) thrombi should also be considered. ${ }^{29}$ Old thrombus is an independent predictor of mortality in AMI patients, which probably relates to their fragile structure and inherent risk of embolization. ${ }^{30}$ For example, MMP content of such thrombi is much higher than in the underlying plaques. Therefore, also thrombus instability appears a matter of concern and the cellular pathways leading to thrombus healing (stabilization) or otherwise embolization or progression to full luminal occlusion need to be further elucidated. Combining morphological characteristics with biomarkers of vulnerable blood, plaque vulnerability, and thrombus instability should result in a pan-arterial approach in which atherothrombotic risk establishment becomes more accurate.

\section{Utility of Biomarkers}

Meta-analyses of prospective studies have established positive associations of circulating levels of fibrinogen, von Willebrand factor (VWF), fibrin D-dimer, and tissue plasminogen activator with risk of coronary heart disease (CHD) and stroke. These data support the concept of coagulation activity as an important contributing mechanism in the processes of atherosclerosis as well as thrombosis. The biomarker data are not yet comprehensive and in particular further studies are required to establish the associations of other coagulation proteins, including those from the contact system, with risk of CHD and CVD. ${ }^{31}$ Given their importance as potential therapeutic targets in CVD, additional biomarkers for VWF, factors VIII, IX, XI, and XII merit further research. ${ }^{32}$

D-dimer level is associated with risk of stroke in patients with $\mathrm{AF}^{33}$ irrespective of anticoagulant drugs. ${ }^{34}$ Prospective 
studies are required to establish its potential role in risk stratification, its relationship to other coagulation activation markers (e.g. prothrombin $\mathrm{F} 1+2$ ), and other biomarkers (e.g. CRP, troponin and pro-NT-BNP). ${ }^{35}$ These may inform future management into two directions. One route concerns the optimized selection of patients who benefit most from anticoagulant treatment (e.g. the discussion in theme 4 on the need for improved selection of patients with AF). A second direction would involve, if possible, dose titration in high-risk subjects. An indication for its potential comes from studies showing that D-dimer level while on anticoagulation predicts ischaemic stroke risk in patients with $\mathrm{AF}^{36}$

\section{Recommendations from Theme 1}

- Future research should focus on identifying biomarkers of ectopic body fat content and distribution and on developing clinical algorithms including ectopic fat assessment for cardiovascular risk stratification.

- Genetic risk stratification, including family history, genegene and gene-environment interactions, as well as comorbidity needs to be explored; integrative data analysis and deep phenotyping are crucial. Proteomic and metabolomic data need to be implemented with genomic data in multicentre trials.

- Develop new definitions and risk assessment strategies for atherothrombosis, potentially combining morphological characteristics with biomarkers of 'vulnerable blood' as well as for plaque destabilization to optimize atherothrombotic risk stratification.

\section{Circulating Cells Including Platelets and Atherothrombosis}

New insights in the diversity and functionality of monocytes (macrophages), leukocytes, and platelets were discussed. The importance of microvesicles (MVs) was recently discussed in this journal. ${ }^{37}$

\section{Leukocytes in Atherothrombosis}

The importance of leukocytes in the pathophysiology of atherosclerosis has been well recognized. $T$ lymphocytes and monocytes/macrophages are abundantly present in atherosclerotic lesions, and strategies that modulate the abundance of these cells show strong effects on the extent of atherosclerosis, at least in mouse models. Also B cells, divided into two main families, provide important protective effects against atherosclerosis (B1), while B2 cells are thought to be atherogenic. ${ }^{38,39}$ Mouse models have also revealed roles of polymorphonuclear cells, most notably neutrophils and mast cells, in the pathophysiology of atherosclerosis. ${ }^{40,41}$ Lineage tracing and specific labelling of leukocyte subtypes in vivo, along with innovative strategies to deplete certain leukocyte subsets in mice, have led to the identification of important contributions of almost any leukocyte subtype tested. ${ }^{39,42-44}$ However, there is still no viable therapeutic or preventive strategy that directly targets leukocytes.
The puzzle is more complex than initially assumed. First, the cell content of the plaque is quite dynamic. Although influx of leukocytes is still believed to be crucial in plaque development, emigration of immune cells from plaques (e.g. to nearby lymphoid organs) also plays a role..$^{45}$ Interestingly, mouse studies revealed that local proliferation outweighs infiltration and is the major determinant of macrophage numbers in the plaque. ${ }^{46}$ Smooth muscle cells (SMCs) that are highly abundant in plaques migrate from the media to the intima, where they proliferate. SMC can also turn into macrophage-like cells with phagocytic activity and the excessive ingestion of lipoproteins causes them to degenerate into foam cells, much like classical macrophages ${ }^{47,48}$ In general, mouse models of atherosclerosis will remain to have utility, but their importance in basic pathophysiologic research might decline, as the emergence of the 'omics' class of technology (e.g. genome-wide association studies, proteomics and RNA sequencing) will gradually take over their roles in human cohorts. This might even lead to the identification of drug principles targeting leukocyte dynamics, once its role in plaque development is fully understood.

\section{Macrophages and Signaling Effects}

Monocytes and neutrophils contribute to venous thrombosis. ${ }^{49}$ Recent studies show that myeloid cell tissue factor (TF) activation in thrombosis is linked to complement activation. ${ }^{50}$ Remarkably, complement factor (C) 3 plays a pivotal role in platelet activation independent of full complement activation downstream of C5. C5 nevertheless is crucial for outer membrane phosphatidylserine exposure and activating TF prothrombotic activity, as previously also demonstrated for complement fixing antibodies causing thrombotic complications in stem cell therapy. ${ }^{51}$ Protein disulphide isomerase pathways are necessary for affinity maturation of TF and phosphatidylserine exposure but is not sufficient to render MV-associated TF fully prothrombotic. ${ }^{52}$ Complement-dependent release of MV from monocytes in LPS-stimulated whole blood produces TF which due to its high affinity is already in complex with its ligand FVIIa.

Venous thrombosis and atherothrombosis are likely driven by distinct but partially overlapping pathophysiological interactions of blood and vessel wall cells. ${ }^{53}$ Atherothrombosis is closely tied to inflammation and interleukin $1 \beta$ (IL1 $\beta$ ) is one of the inflammatory cytokines implicated as a risk factor for arterial occlusive events. Indeed, the recently published CANTOS trial provides proof of concept evidence in showing clinical efficacy of the administration of an anti-interleukin- $1 \beta$ antibody in reducing cardiovascular events. ${ }^{54}$ Macrophages in atherosclerotic lesions are rich sources of TF, but macrophage-expressed TF is also largely in a noncoagulant state. Cell injury signals, specifically ATP triggering the prothrombotic $\mathrm{P} 2 \times 7$ receptor, ${ }^{55}$ induce a thioredoxin-reductase-dependent inflammasome and caspase- 1 activation in primed macrophages. Active caspase- 1 simultaneously generates active IL1 $\beta$ and is responsible for the terminal release step of highly prothrombotic MV carrying active $\mathrm{TF}^{56}$ These data provide evidence for a direct mechanistic coupling of thromboinflammatory pathways. It will be of interest to further study whether this close coupling of inflammation 
and coagulation is common to other activators of the inflammasome. Since macrophages in atherosclerotic lesions express the $\mathrm{P} 2 \times 7$ receptor, $^{57}$ a possible role of this receptor in lesion thrombogenicity should be investigated.

Coagulation also directly influences atherosclerotic lesion progression through effects on leukocytes. ${ }^{58}$ It is notable that expression of coagulation factors by macrophages is not restricted to TF. Lung and peritoneal macrophages express FVII in mouse and $\operatorname{man}^{59,60}$ and tumour macrophages produce FVII and FX. ${ }^{61}$ It is an intriguing possibility that macrophage phenotypes in atherosclerosis are directly regulated by signaling through protease-activated receptors (PARs). PAR2 in particular has been implicated in the regulation of macrophage activation ${ }^{62}$ and chronic inflammation in obesity. ${ }^{63}$ It will be of interest to determine whether coagulation factors synthesized by macrophages have effects on lesions progression, stabilize plaque structure, or contribute to lesion thrombogenicity. While coagulation inhibitors may broadly interfere with thrombosis-related pathways, experimental studies can more precisely define the contributions of intravascular and vessel wall compartments to lesions progression. Translating experimental findings into the clinic will require the development of new diagnostic, biomarker, and imaging approaches based on these mechanistic studies in thromboinflammation.

\section{Red Blood Cells}

In healthy humans, red blood cells (RBCs) occupy approximately 35 to $45 \%$ of the blood volume and elevated haematocrit has been associated with increased risk of both arterial and venous thrombosis (reviewed in Byrnes and Wolberg ${ }^{64}$ ). RBCs have biophysical and biochemical properties that contribute to thrombus formation. For example, RBCs are major determinants of blood viscosity, and increased viscosity has been associated with risk of cardiovascular events. ${ }^{65}$ In vitro studies suggest RBCs promote platelet interactions with the vessel wall,66,67 expose phosphatidylserine, support thrombin generation, ${ }^{68-72}$ bind fibrinogen and fibrin, and decrease clot permeability ${ }^{73}$ and susceptibility to fibrinolysis. ${ }^{74}$ Studies are needed to determine whether RBCs are causative in thrombus formation.

Although RBCs are present in both arterial and venous thrombi, their local function as well as their beneficial or pathological effects during thrombus evolution remains unknown. For example, heme deposited by decomposing or phagocytized RBCs may alter recruitment or function of other blood cells within the clot. Compaction of RBCs by platelet-mediated contractile force may stabilize thrombi and prevent embolization, but may prolong thrombus resolution. Experimental systems that incorporate blood flow, RBCs, platelet-mediated contraction, thrombin generation, and fibrinolysis are needed to understand how RBCs influence thrombus formation and stability.

\section{Platelet Pleiotropy: Different Platelets, Different Functions}

The concept of interplatelet heterogeneity ${ }^{75}$ is receiving increased interest. Platelets from an individual donor can differ in glycoprotein receptors expression levels and activation.
Circulating platelets differ in mRNA content and capacity to translation, depending on their life time. ${ }^{76}$ Furthermore, platelets undergoing secretion can differ in the process of secretory granule fusion and exocytosis. ${ }^{77}$ On the other hand, platelets assembling in a growing thrombus diverge into (1) aggregated and contracted platelets of the thrombus core; (2) transiently adhered platelets of the outer thrombus shell; and (3) highly activated, procoagulant platelets in thrombus patches. ${ }^{75}$ This raises the intriguing question if the known pleiotropy in platelet functions implies that different populations of platelets are 'specialized' in carrying out different functions. Several key elements in the life of platelets that are worth further investigation can be identified:

1. Difference between individual megakaryocytes and platelets. Despite visualization of (pro)platelet production in the bone marrow, ${ }^{78}$ it is unknown how megakaryocytes regulate the numbers of receptors per formed platelet. A current assumption is that a certain megakaryocyte produces similar (pro)platelets, but cultured megakaryocytes, even when produced from a single-cell clone of hematopoietic precursors, show a remarkably large intercellular variability in surface receptor expression. ${ }^{79}$ This raises the possibility that different megakaryocytes in the bone marrow can form different 'types' of platelets.

2. Priming of platelets (macroenvironment). Due to the presence of circulating hormones or other biomolecules, platelets can be primed to become more or less responsive to agonists. ${ }^{80}$ Priming can occur rapidly, and be followed by a prolonged period of sensitization or desensitization. ${ }^{81} \mathrm{Gi}$ ven the differences in makeup of individual platelets, some platelets may be more prone to priming than others. Both acute and chronic disease conditions may act as primers, either through exposure to tissue damage or through inflammatory mediators or pathogens.

3. Platelet populations in a thrombus (microenvironment). Densely aggregated and contracted platelets have been observed in the thrombus core, surrounded by an outer shell of more loosely attached platelets. ${ }^{82}$ Surrounding the aggregated platelets, patches of highly activated platelets are seen with a specialized function in coagulation. ${ }^{75}$ Likely, the microenvironment (e.g. the direct exposure of platelets to collagen and thrombin) plays a role in this platelet heterogeneity.

4. Platelet age and size. Platelets circulate in the blood stream for 7 to 11 days. There is debate whether newly formed platelets are larger in size and more active than aged platelets. Such associations have been measured, but these are weak. Increased mRNA content of the younger platelets may direct platelet function and fate and even the vesiculation of platelets.

5. Platelet heterogeneity in vivo versus in vitro. The properties and even the populations of isolated platelets can differ (e.g. with respect to priming) from the properties of platelets circulating in the blood. Moreover, in vivo preactivated platelets will be more prone to being cleared than inhibited platelets, whereas both can stay in suspension after isolation. ${ }^{81}$ This brings about a need for new 
technologies to study single-cell activation properties of platelets in vivo and in vitro, and a requirement for standardized isolation of platelets without affecting their priming state.

\section{Recommendations from Theme 2}

- Address mechanisms of leukocyte plasticity, migration, and transformation in murine atherosclerosis; various 'omics' technologies have the potential to take over the role of mouse models in human cohorts.

- Characterize the role of haemostatic factors in macrophages related to inflammation and atherothrombosis; develop mechanism-based biomarkers.

- Investigate the causal contribution of RBCs in thrombus formation.

- Incorporate whole blood flow in experimental systems to assess how RBCs influence thrombus formation and stability.

- Improve knowledge on platelet heterogeneity, how this translates into the formation of platelet populations by megakaryocytes, how to translate from single-cell (platelet, megakaryocyte) assays to the in vivo situation? Investigate how platelet priming fits into the pathogenesis of thrombotic disease (cause or consequence?).

\section{Coagulation Proteases, Fibrin(Ogen) and Thrombus Formation}

\section{Factor XI}

Factor XI (FXI) is a pivotal protein in the coagulation cascade, as it links the contact system with thrombin and fibrin formation, and it also determines the flux through the coagulation cascade after TF exposure via thrombinmediated FXI activation. ${ }^{83}$ Drugs targeting FXI can be effective for thrombosis prevention, but there are no data showing that FXI targeting is useful in the treatment of thrombosis. An intervention study in humans who underwent total knee replacement demonstrated that reducing FXI levels by antisense oligonucleotides (ASO) was effective and safe. ${ }^{84}$ This study was carefully chosen, since knee replacement introduces a medical device, which likely activates the contact system. Furthermore, the TF concentration in knees is very low, meaning that the amplification of thrombin formation via FXI becomes relatively important. ${ }^{85}$

The bleeding tendency in FXI deficiency is most often trauma related especially in tissues with high local fibrinolytic activity, while spontaneous bleeding is rare, and therefore low levels of FXI appear to be safe. Preclinical and clinical studies suggest that complete deficiency is not necessary to effectively prevent thrombosis; a level of 20 to 30\% FXI is effective and expected to result in less bleeding compared with complete inhibition.

The optimal approach to target FXI is still debated. ${ }^{86}$ Vaccination (probably not reversible) and ASO have the disadvantage of a slow onset of action. The use of small molecules and (monoclonal) antibodies requires additional studies, also considering potential off-target effects of these approaches.

\section{Coagulation (Factor XI) and Its Link with Platelets and Hypertension: A Novel Risk Mechanism}

Recent experimental and early clinical data suggest that targeting FXI could be effective in treating vascular inflammatory conditions that go beyond treating clotting disorders. FXI deficiency improved survival in polymicrobial sepsis ${ }^{87}$ and protected from disease progression in atherosclerotic mice. ${ }^{88}$ Individuals with congenital FXI deficiency are partially protected from myocardial infarction and stroke, both sequels of chronically increased blood pressure. ${ }^{89}$ FXI ASO application prevented arterial hypertension and reduced established hypertension in animal models. This effect was connected to interruption of the thrombin-FXI amplification loop involving glycoprotein (GP)Ib $\alpha$ on platelets, attenuating the proinflammatory state of platelets and reducing vascular accumulation of inflammatory leukocytes, endothelial dysfunction, and tissue remodelling in response to high blood pressure. The FXI-dependent platelet-localized amplification of FII was validated in humans with uncontrolled hypertension. ${ }^{90}$

Since thrombin propagation is essential in the observed non-clotting-related effects, thrombin signaling, which is likely mediated through PARs, must be further explored. Since PAR-1 is expressed on monocytes, endothelial cells and SMCs alike, the thrombin-signaling through PAR-1 needs to be investigated in greater detail to understand possible beneficial off-target and/or disease modifying effects of direct thrombin inhibitors like dabigatran. However, RELY investigators ${ }^{91}$ so far have not reported on alterations in blood pressure in patients on dabigatran treatment.

If the FXI-mediated effects were all related to propagation of thrombin formation, patients with haemophilia A or B should also have lower blood pressure. However, the contrary is the case; this may be due to inflammatory responses associated with repeated episodes of severe bleeding that might potentially override a putative 'antihypertensive' effect of FIX or FVIII deficiency. An additional potential target is the GPIba, the receptor on platelets to which thrombin as well as FXI but also the MAC-1 integrin on leukocytes and VWF can bind.

FXI has a striking homology to pre-kallikrein (PK). Depletion of FXI (e.g. by an ASO approach) might cause counterregulatory upregulation of PK with ensuing activation of bradykinin, which might directly cause vasodilation and blood pressure lowering in a nitric oxide-dependent manner. It should be evaluated whether targeting of C1-esterase inhibitor, a natural FXIa inhibitor, would affect blood pressure. Furthermore, using small molecules targeting FXIa ${ }^{92}$ should be considered to evaluate whether inactivation of the active protease is equally effective in influencing blood pressure as the ASO approach. This is of interest, as nonspecific effects of ASOs on platelet count and function ${ }^{93}$ could impact on vascular function independently of the protease activity of FXI. Datasets of the aforementioned FXI ASO clinical trial and population-based cohorts (e.g. Clalit Health Service database, ${ }^{89}$ Gutenberg Health Study ${ }^{94}$ ) should be explored for associations of FXI activity or single nucleotide polymorphisms in the FXI gene with vascular function, hypertension, or incident CVD. 


\section{Factor XII, Polyphosphates, Prekallikrein and High- Molecular-Weight Kininogen}

The FXII-driven contact system and its endogenous activator polyphosphate (polyP) play important roles in thrombosis. ${ }^{95}$ In contrast to FXI deficiency, FXII-deficient humans do not suffer from any abnormal bleeding. Targeting the contact system or polyP represents promising therapeutic targets for prevention of or interference with thrombotic disorders. ${ }^{96,97}$ In addition, activated FXII induces potent inflammatory responses via activation of the kallikrein-kinin system resulting in the formation of the inflammatory mediator bradykinin. ${ }^{98}$ The dual role of FXII in thrombosis and inflammation makes it an attractive therapeutic drug target for anticoagulation without any bleeding risks and additional anti-inflammatory activities. ${ }^{99,100}$

Prekallikrein circulates in plasma bound to high-molecularweight kininogen (HK), the bradykinin precursor. Upon activation by FXIIa, prekallikrein is converted to plasma kallikrein and then reciprocally amplifies further FXII cleavage that in turn produces additional plasma kallikrein. ${ }^{101,102}$ Similar to FXII, plasma kallikrein-deficient mice have an antithrombotic phenotype and do not bleed excessively. ${ }^{103}$ As plasma kallikrein functions mostly as an amplifier of the coagulation cascade, its deficiency can be overcome by strong contact activators which limits its potential use as target for anticoagulation. ${ }^{98}$ However, targeting plasma kallikrein has proven beneficial effects for interference with bradykinin-driven inflammation such as hereditary angioedema. ${ }^{104,105}$

Inhibition of HK seems to be another promising strategy for safe thromboprotection as suggested from mouse models. In contrast to humans, mice have two kininogen genes and ablation of kininogen 1 ( $m k n g 1^{-1-}$ mice) protects from experimental arterial thrombosis without causing bleeding. ${ }^{106}$ Consistently, a patient with plasma kininogen activity of less than $1 \%$ did not bleed. ${ }^{106}$ While serine proteases are targetable by small molecule inhibitors that bind into the enzymatic pocket, strategies for interference with HK or HK expression should be further investigated.

PolyP, a linear polymer consisting of a few to several hundred residues of orthophosphate linked by phosphoanhydride bonds, initiates coagulation in a FXII-dependent manner. ${ }^{107}$ Platelets contain two pools of polyphosphate. Short-chain soluble polyP with low FXII activating capacity are released from platelet dense granules. The majority of platelet polyP, however, forms nanoparticles (similar to other FXII activators such as kaolin or ellagic acid) with divalent metal ions (mostly as $\mathrm{Ca}^{2+}$ ) that are retained on the surface of platelets and potently activate FXII. ${ }^{107}$ The role, structure, and composition of these nanoparticles in thrombotic conditions warrant further investigation.

\section{Factor XIII}

Factor XIII is unlike other coagulation enzymes in its ability to crosslink, rather than cleave, proteins within the clot. FXIII (FXIIIa) activity is essential for clot biochemical and mechanical stability. ${ }^{108}$ Several FXIII polymorphisms appear to modify thrombosis risk; ${ }^{109,110}$ these function, in part, through complex interactions that mediate the kinetics of
FXIII activation and fibrin crosslinking. ${ }^{111,112}$ FXIII activity also promotes retention of RBCs within clots during plateletmediated clot contraction. ${ }^{113}$ However, fundamental mechanisms in FXIII biology and biochemistry and its impact on thrombus biophysical characteristics remain unclear.

Although studies suggest FXIIIa can be proteolytically inactivated, ${ }^{114}$ endogenous inhibitors of FXIIIa have not been identified. Importantly, currently available FXIIIa inhibitors lack the pharmacological properties necessary for in vivo investigations.

FXIII is found in both plasma and cellular compartments, but the relative roles of plasma and platelet FXIII in platelet function, fibrin crosslinking, and thrombus composition and stability are poorly understood.

Differences in FXIII expression between humans and mice should be considered when using animal models.

\section{Fibrin Network Structure}

Fibrinogen conversion to fibrin is essential for haemostasis. Formation of clots with abnormal structure and stability is associated with haemostatic and thrombotic disorders, including both arterial and venous thrombosis/thromboembolism. ${ }^{31}$ Clots with overly dense fibrin network structure have been associated with enhanced mechanical and biochemical stability and increased risk of thrombosis. ${ }^{65-68}$ These observations indicate that the clot structure may be a biomarker of haemostatic and thrombotic potential.

Most studies use in vitro methods to assess plasma clot structure in the absence of cells, but this approach fails to reveal contributions of vascular and blood cells to clot formation and function; these include both procoagulant and fibrinolytic activities produced by local blood and vascular cells, and mechanical forces imparted by platelets during clot contraction.

\section{Platelet-Fibrin Interactions and Clot Architecture}

Knowledge of fibrin interactions with platelets and their respective interactions with other blood cells is incomplete. Platelets bind fibrin through activated $\alpha_{\text {IIb }} \beta_{3}$, which also binds fibrinogen. However, recent studies show that fibrin, but not fibrinogen, binds GPVI and activates platelets. ${ }^{115,116}$ The thrombus is not homogeneous, but composed of a core of strongly activated platelets and a periphery of more loosely activated platelets. ${ }^{117}$ It is possible that combined collagen and fibrin interactions with platelets drive thrombus core formation, while the interaction of fibrin with platelets plays a role in determining the thrombus periphery.

1. Filling the void: there is a need for novel in vitro and in vivo models to probe interactions between platelets and coagulation. However, studying platelet-fibrin interactions is practically challenging, as the fibrin mesh that is formed eliminates several techniques. Vice versa, platelet aggregates interfere with clotting assays. An intermediate stage of fibrin protofibrils and oligomers precede the gelation point. ${ }^{118}$ Further studies are required to determine platelet interactions with these fibrin species. 
2. Novel GPVI-fibrin interactions shed new light and should be investigated in diseases of thrombosis and haemostasis. Recent data indicate that collagen and fibrin bind distinct GPVI epitopes (Onselaer MB et al, PhD, unpublished data), suggesting that it is possible to specifically target each ligand interaction. GPVI polymorphisms have also been associated with venous thromboembolism in genome-wide association studies. ${ }^{119}$ It would be interesting to investigate whether GPVI polymorphisms that result in less active GPVI signaling are also associated with decreased fibrin-GPVI interactions.

3. There could be other coagulation and platelet interactions that are currently unknown. Proteins such as $\mathrm{vWF}^{120}$ fibronectin, ${ }^{121}$ FXIII, ${ }^{122,123}$ and $\alpha_{2}$-antiplasmin ${ }^{124}$ are incorporated into the fibrin clot and their role in platelet interactions with the clot in the context of the clot network are incompletely understood. Furthermore, platelets express several fibrinolytic proteins and FXIII on their surface, ${ }^{125,126}$ which may interact with the surrounding fibrin network.

4. Interactions with red and white cells. There is evidence for the binding of red cells to fibrinogen ${ }^{127,128}$ and platelets. ${ }^{129,130}$ The implications of these interactions deserve further study. Neutrophils contribute to thrombosis through the production of NETs. ${ }^{131}$ DNA and histones have been shown to impart resistance to fibrinolysis. ${ }^{132}$ How DNA and histones interact with fibrin at the fibre level is poorly understood. White cell incorporation or invasion into thrombi may also contribute to thrombus resolution through the production of elastase, which has been shown to degrade fibrin and FXIII. ${ }^{133,134}$

\section{Recommendations from Theme 3}

- Address the relevance of FXI for treatment of thrombosis and thromboinflammatory disorders; a 'safe' lower level of FXI targeting thrombotic complications remains to be determined. Off-target effects of inhibiting FXI need to be considered.

- Undertake further studies on FXI induced increased thrombin production and PAR-mediated cell signaling; these should consider upregulation of PK-mediated activation of the bradykinin pathways; population-based cohorts or large trials with anticoagulants should be explored for signals of blood pressure lowering effects or changes in incident CVD linked to FXI or other clotting protease activity.

- Address the dual role of FXII in thrombosis and inflammation in different disorders; investigate strategies for interference with $\mathrm{HK}$ or $\mathrm{HK}$ expression; investigate the role of PolyP nanoparticles on platelets.

- Explore the fundamental mechanisms in FXIII biology and biochemistry and its impact on thrombus biophysical characteristics; development of FXIII(a) inhibitors would facilitate studies to investigate FXIII(a) function in haemostasis and thrombosis.

- Development of technologies to image fibrin structure and biophysical characteristics in the presence of blood cells and in thrombi formed in vivo would yield important insights; differences in fibrin network structure between species (e.g. humans versus mice) should be considered in studies of fibrin structure and function in health and disease.

- Study the relationships between abnormal fibrin structure and functional consequences, including susceptibility to fibrinolysis and mechanical deformability, which should involve new technologies to image fibrin structure and biophysical characteristics in the presence of blood cells and in thrombi formed in vivo.

- Investigate whether there are additional aspects of the interaction between platelets, fibrin (e.g. fibrin-GPVI interactions), and red and white blood cells that play key roles in thrombosis and haemostasis.

\section{Preventive and Acute Treatment of Atherothrombosis and Arterial Embolism: Novel Ways and Tailoring}

\section{Inhibition of Protease-Activated Receptor-Mediated Cell Signalling as Antithrombotic Strategy}

Despite the prematurely halted TRACER study due to increases in the risk of moderate and severe bleeding events in stroke patients, pharmacologic blockade of PAR1 is still potentially an attractive target for the prevention of several cardiovascular pathologies, including acute coronary syndrome, chronic secondary prevention of ischaemic events, and peripheral artery disease (PAD). ${ }^{135,136}$ In the TRA2 P-TIMI 50 study, the PAR1 antagonist, vorapaxar, did meet primary endpoints with significant reductions in major adverse coronary events (MACEs) in secondary prevention in nonstroke patients with prior myocardial infarction and PAD. In particular, the subgroup of patients with prior MI also demonstrated a significant reduction in cardiovascular death and ischaemic events. ${ }^{137}$ Despite documented improvements in MACE reduction and approval by Food and Drug Administration, vorapaxar has not seen widespread use, especially in the subjects with prior MI, due to the perceived elevated bleeding risk (especially intracerebral haemorrhage). The use of vorapaxar on top of dual antiplatelet therapy (e.g. triple antiplatelet therapy) may likely have contributed to the increase in incidence of bleeding events. Studying the effects of vorapaxar as monotherapy or dual therapy might reveal reduced bleeding risk and would be worth testing especially in subjects with prior MI.

One potential explanation of these increased intracranial bleeds on triple therapy might be that akin to TF and thrombomodulin, PAR1 is differentially expressed in endothelial cells of the brain, ${ }^{138}$ thereby giving rise to different integrin/leukocyte adhesion, regulation, and haemostatic functions. Another issue with vorapaxar is that it displays functionally irreversible binding to PAR1 with pharmacodynamic antiplatelet effects of 4 to 8 weeks. ${ }^{139}$ As reversibility is important to mitigate bleeding risk, vorapaxar may not be practical to use in patients with heightened risk of bleeding (e.g. older patients, those with low body weight, or uncontrolled hypertension). Another interesting pharmacologic effect to be addressed is why a single dose of vorapaxar exhibits such a long lasting anti-PAR1 platelet 
effect well after replenishment with fresh platelets 8 to 10 days after drug administration. Does this imply that vorapaxar binds to megakaryocyte PAR1 and somehow changes the megakaryocyte behaviour leading to a 'memory' effect in the megakaryocyte due to phenotypic switching or imprinting? Does vorapaxar alter PAR1 expression or are other critical platelet signaling components downregulated or altered to suppress long-term PAR1 function in the nascent platelets? The new PAR1 pepducin inhibitor, PZ-128, which has a fast on-rate and improved reversibility of recovery of PAR1 platelet function, ${ }^{140}$ and may provide a more favorable balance of efficacy and safety, is currently being evaluated in the phase 2 TRIP-PCI clinical trial in the United States.

Aside from PAR1, is the lower affinity PAR4 thrombin receptor inherently a better target than PAR1 because PAR4 blockade causes less bleeding, or is PAR4 a poor target because PAR1 is the high-affinity thrombin receptor ${ }^{141}$ ? Success in targeting PAR4 or the PAR1-PAR4 heterodimer ${ }^{142}$ will require achieving efficacy even if safety concerns are not an issue. Recent identification of a superactive PAR4 polymorphism in transmembrane domain-2 (TM2) in blacks would suggest enriching clinical trials with appropriate populations to fully understand the pharmacogenomics of PAR4 inhibitors. ${ }^{143}$

\section{Optimizing Antiplatelet Therapy by Platelet Function Monitoring}

Dual-antiplatelet therapy, consisting of aspirin and a $\mathrm{P}_{2} \mathrm{Y}_{12}$ inhibitor, is the mainstay of treatment for patients with coronary artery disease undergoing percutaneous intervention, to prevent stent thrombosis. ${ }^{144,145}$ However, some patients continue to have thrombotic events while on antiplatelet therapy, while others suffer from bleeding. ${ }^{146}$ The degree of $\mathrm{P}^{2} \mathrm{Y}_{12}$ inhibition as measured by platelet function tests (PFTs) has been related to the risk of both thrombotic and bleeding events and has led to the concept of a therapeutic window for optimizing antiplatelet therapy. ${ }^{146-148}$ Several large clinical trials have investigated the value of PFT-based tailoring of antiplatelet therapy. These trials, such as GRAVITAS, TRIGGER$\mathrm{PCI}$, and ARCTIC, all failed to prove that intensifying $\mathrm{P}_{2} \mathrm{Y}_{12}$ inhibitor therapy prevents thrombotic events in patients with a low response to $\mathrm{P}_{2} \mathrm{Y}_{12}$ inhibitors (high on-treatment platelet reactivity [HTPR]). ${ }^{149-151}$ The ANTARCTIC trial was the first to also include a de-escalation arm of antiplatelet therapy in cases of low on-treatment platelet reactivity (LTPR) to prevent bleeding in the elderly, but this also appeared ineffective. ${ }^{152}$ Results of the second de-escalating trial, TROPICAL-ACS, are expected in the third quarter of $2017 .{ }^{153}$

So, have any of these studies actually proven that the concept of individualizing antiplatelet therapy based on PFTs does not improve clinical outcome? Members of the workshop felt that this cannot be concluded, due to limitations of both the trial designs and PFTs. Recognized drawbacks of the trial designs include (1) the study protocols regarding intensification of $\mathrm{P}_{2} \mathrm{Y}_{12}$ inhibition mainly allowed a singular switch to another drug or dose, (2) the studies had low statistical power because of a low incidence of primary endpoints, and (3) patients with a higher risk of recurrent events were mostly excluded (e.g. STEMI). ${ }^{147}$ The importance of this last limitation is underpinned by two recent metaanalyses indicating that both the predictive value of platelet reactivity for thrombotic events, and the benefit of PFTbased tailoring of therapy, is dependent on the patient's cardiovascular risk profile. ${ }^{154,155}$

Limitations of PFTs also significantly hinder the measurement of platelet reactivity and optimization of treatment. Widely used PFTs include light transmission aggregometry (LTA), PFA-200, multiplate, and the only true point-of-care test in use, the VerifyNow. Most importantly, these assays do not reflect normal physiological platelet function. Platelets tend to be activated with single agonists while in vivo multiple stimulation occurs, the influence of coagulation or fibrinolysis is not usually assessed, pleiotropic effects of the $\mathrm{P} 2 \mathrm{Y}_{12}$-inhibitors cannot be measured, and with the exception of PFA-200 platelet aggregation is measured under low shear conditions. ${ }^{156}$ Another limitation of the widely used PFTs concerns the large influence of preanalytical variables on the test results, including the type of anticoagulant used, delay time from blood withdrawal to measurement, and concentrations of agonists used. ${ }^{156}$ Finally, current PFTs lack assay standardization and consensus regarding optimal cut-offs for HTPR and LTPR. ${ }^{147}$ One of the ongoing activities of the ISTH Platelet Physiology SSC is to publish new guidelines for monitoring of $\mathrm{P}_{2} \mathrm{Y}_{12}$-inhibition (http://www.isth.org/members/group.aspx?id=100371).

\section{Anticoagulation in Atrial Fibrillation: To Treat or Not to Treat, That Remains the Question!}

Patients with AF should ideally be treated by a team of cardiologists and specialized nurses ${ }^{157}$ - which treats comorbidities and decides on anticoagulation therapy. Current ESC guidelines recommend using the $\mathrm{CHA}_{2} \mathrm{DS}_{2}$-VASc score to guide initiation of anticoagulation therapy in patients with AF. ${ }^{158}$ However, there is room for improvement in the identification of patients who need and tolerate anticoagulation, to prevent overtreatment and reduce bleeding events, respectively.

The risk factors that are part of the $\mathrm{CHA}_{2} \mathrm{DS}_{2}$-VASc score should be further specified: for example, currently it is not defined whether left ventricular hypertrophy on echocardiography should be counted as 'hypertension' and whether coronary artery disease on CT angiography should be counted as 'vascular disease'.

There is no consensus on the use of anticoagulation in patients with one risk factor $\left(\mathrm{CHA}_{2} \mathrm{DS}_{2}\right.$-VASc score of 1 in men, 2 in women). The ESC guidelines suggest considering starting anticoagulation, ${ }^{158}$ while the AHA/ACC suggests considering not to start anticoagulation. ${ }^{159}$ Recent large-scale reports show differing results: there are high stroke rates in patients with one risk factor not on anticoagulation, ${ }^{160}$ while the bleeding risk on warfarin is exceptionally high and probably higher than the stroke risk. ${ }^{161}$ Additionally, AF pattern (i.e. paroxysmal or persistent) may be considered in the decision, as it may reflect underlying pathology and hence associate with stroke and bleeding risk. ${ }^{162}$ 
Biomarkers may be used to improve risk stratification (e.g. the Age Biomarkers Clinical History [ABC] score), ${ }^{163}$ in which NT-proBNP and troponin are incorporated. However, it is currently unknown how this score should be implemented in daily practice.

Both the $\mathrm{CHA}_{2} \mathrm{DS}_{2}$-VASc score and the $\mathrm{ABC}$ score identify those patients who are susceptible to vascular disease, such as stroke, rather than the patient's clotting tendency. However, it has been shown that hypercoagulability may be the underlying process leading to $\mathrm{AF}^{164}$ even in vascularly healthy patients. ${ }^{165}$ Future risk stratifying strategies may need to include measurements of hypercoagulability.

There are several imaging strategies that may enhance identification of patients with a high stroke risk. With transoesophageal echocardiography, the presence of highrisk echocardiographic features can be assessed, ${ }^{166}$ while echocardiography, cardiac CT, or MRI can be used to assess left atrial appendage morphology, ${ }^{167}$ all of which may enhance the identification of those patients with a phenotype prone to stroke.

Current risk scores are validated only for patients with AF which is recorded on ECG or Holter. Cardiac implantable electronic devices (CIEDs) continuously monitor the (atrial) heart rhythm. In case a CIED registers an atrial high rate event, it is currently unknown whether anticoagulation should be started. The ongoing randomized NOAH (NCT02618577) and ARTESiA (NCT01938248) trials will provide valuable answers for this category.

\section{How to Handle the Risk of Anticoagulant Therapy?}

For many years anticoagulation was based on vitamin $\mathrm{K}$ antagonists (VKA). Monitoring of anticoagulant treatment is done via regular measurements of the international normalized ratio (INR) in a secondary care setting, at least in several countries. These specialized anticoagulation centres in which knowledge and experience with VKA treatment is present play a key role as coordinator of anticoagulation therapy.

The field of anticoagulation therapy is evolving. Non-VKA oral anticoagulants (NOAC) have shown to be at least as effective and safer as VKA in large trials, ${ }^{91,168-170}$ and are now changing clinical practice. Dabigatran, rivaroxaban, apixaban, and edoxaban are replacing VKA as first choice treatment for several indications. The possibility to prescribe different types of oral anticoagulants for similar indications is making anticoagulant treatment more complex.

The balance between the risk of thrombosis and the risk of bleeding remains an important concern in patients receiving anticoagulant therapy. Due to a more predictable pharmacological profile, routine monitoring is not required for NOACs. However, this should not preclude regular followup to oversee safety and efficacy of treatment. ${ }^{171}$ Currently, there is no standardized follow-up available for patients on NOAC therapy. The question rises how this follow-up should be implemented in existing health care systems that are currently based on VKA management. ${ }^{171,172}$ We propose a solution for NOAC follow-up, designed to increase treatment efficacy and safety, based on expanding the capacity and capability of current anticoagulation centres, without a big increase in costs.

The current anticoagulation centres are well trained and equipped to adequately monitor and guide patients on VKA, reaching high time in therapeutic range. ${ }^{173}$ These centres are local and give centralized coagulation care to a small population. By educating specialist coagulation nurses and physicians, their knowledge on NOACs can be increased. Specific software tools and checklists can help nurses with systematic assessment of patients on NOACs. A physician should be available for consultation, but overall the anticoagulant care should, ideally, remain nurse based. Nurses should monitor several aspects, such as the following:

- Kidney and hepatic function.

- Compliance to drugs, which can also be checked via information from the pharmacy.

- Weight.

- Blood pressure.

- Adverse events during treatment, i.e. bleeding events.

- Haemoglobin and platelet counts.

- Reassessing the indication for anticoagulation.

Furthermore, haemostasis centres are needed, which should be regional and should be located in a medical centre with a multidisciplinary team, for example consisting of a haematologist, cardiologist, neurologist, and a gastroenterologist.

\section{Organ Specificity of Anticoagulant Effects}

The pattern of bleeding with oral anticoagulants differs by agent. ${ }^{174}$ Compared with warfarin, all of the NOACs reduce intracranial bleeding, some NOACs are associated with increased gastrointestinal (GI) bleeding, and some are associated with abnormal uterine bleeding. ${ }^{175}$ Several mechanisms have been proposed to explain the organ-specific effects of different oral anticoagulants.

First, the mechanisms of action of VKA compared with NOACs: VKA inhibit the production of vitamin K-dependent coagulation proteins, whereas NOACs selectively target coagulation factors Xa or IIa. ${ }^{176,177}$ By targeting multiple coagulation factors, VKAs appear to produce greater inhibition of thrombin generation than the NOACs, ${ }^{178}$ which may in part explain why they are associated with a higher risk of bleeding. However, this does not explain organ-specific differences in bleeding.

The second mechanism is related to physiologic differences between vascular beds of the brain, gastrointestinal tract, and uterus. The brain is rich in TF and haemostasis is dependent both on expression of TF on subendothelial membranes and on low levels of tissue factor pathway inhibitor (TFPI), ${ }^{179}$ an inhibitor of the TF/VIIa complex. By inhibiting factor VII, VKAs prevent the formation of the TF/VII complex and thereby suppress haemostatic mechanisms in the brain, whereas this mechanism is unaffected by the NOACs. This may explain the reduction in intracranial haemorrhage with NOACs compared with warfarin. In the uterus, animal studies suggest that factor 
Xa is important in the regulation of haemostasis. This may explain why factor Xa inhibition by rivaroxaban is associated with an increase in abnormal uterine bleeding compared with warfarin. ${ }^{180}$

The third mechanism is relevant to excess GI bleeding seen with several NOACs. The integrity of the GI mucosa can be disrupted by intraluminal factors, ${ }^{181}$ and this allows uptake of drugs from the lumen. VKAs exert their anticoagulant effect by inhibiting vitamin $\mathrm{K}$ epoxide reductase, which requires $\mathrm{ab}-$ sorption from the gut into the systemic circulation, whereas NOACs are only partially absorbed from the gut and residual drug can exert effects locally on the GI mucosa leading to bleeding. ${ }^{174,179,182}$

The ESC guidelines ${ }^{158}$ for stroke prevention in AF recommend use of the HAS-BLED score to predict bleeding, but this score is only weakly predictive. One possible contributor to its poor predictive value is that it fails to take into account organ-specific differences in bleeding risk. The future development of separate risk scores for intracranial, GI, and uterine bleeding may improve risk prediction but might also increase complexity because of difficulties in integrating the information for individual patients.

\section{Toward Individualized Optimized NOAC Therapy}

Although routine coagulation monitoring is not required in patients taking NOAC, certain clinical situations require guidance on the intensity of anticoagulation. Currently, there is no consensus on which clinical situations would benefit from such occasional monitoring. Some experts propose specific cut-offs in plasma concentration equivalent to reduce the risk of haemorrhagic complications in the perioperative setting or to guide the administration of reversal agents. $^{183-185}$

Importantly, these different clinical situations require different test characteristics. For emergency situations, the question is whether any remaining anticoagulant effect is still present and a sensitive test with short turnaround time and a 24-hour availability is essential. Classical coagulation tests, such as PT, aPTT, and thrombin time, have important limitations. ${ }^{186-188}$ For more robust and quantitative purposes, specific assays are available, including diluted thrombin time (dTT) or Ecarin chromogenic assay (ECA) for dabigatran, and NOAC calibrated chromogenic anti-Xa assays for FXa inhibitors. ${ }^{172,175}$ The turnaround time of these specialized assays is similar to the one of routine tests making them preferable. ${ }^{189}$ However, rapid, point-of-care, whole blood tests for use in emergency situations would be desirable, while other specialized assays such the thrombin generation test, the thromboelastography or ROTEM, and other microfluidic assays might offer potential in the near future. $^{190}$

Laboratory measurement is useful not only in emergency situations but also for eventual dose adjustment purposes. Although the clinical trials with NOACs proved the safety of the fixed dose policy, ${ }^{91,168-170,191-195}$ the observed considerable interindividual variation in drug levels in pharmacokinetic studies and clinical trials suggests that dose adjustment guided by laboratory assays may be appropriate in some circumstances (provided that registered doses are used). ${ }^{196-205, \text { a }}$

At present, however, there are neither established therapeutic ranges nor is there evidence-based data supporting the laboratory approach. At the same time, on-therapy ranges are available from the large phase $2 / 3$ studies, $201,206-208, \mathrm{~b}$ which can be considered in daily practice.

Although this proposal did not reach consensus, we propose that future studies should focus on the definition of a 'therapeutic window', and explore the possibilities of tailoring the dose based on these safety margins. This approach may improve the benefit-risk ratio in elderly/frail patients.

\section{Other New Anticoagulants}

The ideal anticoagulant should prevent thrombosis without increasing bleeding risk. Additional features could include low renal clearance, minimal drug-drug/drug-food interactions, good oral bioavailability, and an effective reversal agent, if required. Importantly, the residual major bleeding risk with current anticoagulant drugs is of the order of 2 to $3 \%$ per year in patients with $\mathrm{AF}^{209-211}$ and $1 \%$ in patients with VTE. ${ }^{212}$ Moreover, the number needed to treat with a NOAC for preventing one major bleeding event, compared with VKA, remains high $(>100) .^{211,212}$ Until recently, clinical anticoagulation has been oversimplified, without addressing organ-specific processes of bleeding and thrombosis and the differences in pathogenesis across various clinical scenarios, as exemplified by bleeding patterns with NOACs. ${ }^{211,212}$ Thus, during drug development, indication-specific targeting should be considered. This includes, for example, researching contact pathway inhibition for indwelling artificial surfaces such as catheters or mechanical heart valves, and taking into account oscillation of drug levels and lack of protective mechanisms present in normal vessels walls.

NOACs have yet to challenge VKA treatment in rarer sites of thrombosis, such as cerebral venous sinus thrombosis and chronic portal vein thrombosis. Patients with mechanical heart valves are a group in need of new anticoagulants. The

\footnotetext{
a Food and Drug Administration. Eliquis-Clinical Pharmacology and Biopharmaceutics Review(s) 2012 [updated October 25, 2016]. Available from: http://www.accessdata.fda.gov/drugsatfda_docs/nda/2012/202155Orig1s000ClinPharmR.pdf. European Medicines Agency. Eliquis-EMEA/H/C/002148/X/04/G 2012 [Available from: http://www.ema.europa.eu/docs/en_GB/document_library/EPAR_-_Assessment_Report_-_Variation/human/ 002148/WC500136575.pdf].

b European Medicines Agency. Xarelto-Summary of Product Characteristics 2016 [updated October 14, 2016]. Available from: http://www.ema.europa.eu/docs/en_GB/document_library/ EPAR_-_Product_Information/human/000944/WC500057108. pdf; European Medicines Agency. Eliquis-Summary of Product Characteristics 2017 [updated February 22, 2017]. Available from: http://www.ema.europa.eu/docs/en_GB/document_library/EPAR_-_Product_Information/human/002148/ WC500107728.pdf; European Medicines Agency. Pradaxa-Summary of Product Characteristics 2017 [updated January 12, 2017]. Available from: http://www.ema.europa.eu/docs/en_GB/ document_library/EPAR_-_Product_Information/human/ 000829/WC500041059.pdf.
} 
optimal anticoagulant for patients with cancer requires further evaluation. Some of these issues may be addressed by clinical trials with contemporary anticoagulants already approved for other indications rather than by development of new anticoagulants.

Haemostasis and thrombosis are generally considered to be manifestations of the same enzymatic and cellular processes. Consequently, dissociation of antithrombotic and bleeding effects might not be achievable, except perhaps for the use of anti-FXIIa targeted therapy that should, at least from a theoretical point of view, be unaccompanied by a bleeding risk. ${ }^{100}$

Recent studies indicate that the 'anatomy of a clot' is not homogeneous with compartmentalization of a clot into a core and a shell. ${ }^{82}$ If the anatomy of haemostatic clot as opposed to a thrombotic clot is different, it is possible that novel therapeutic molecules that are able to exploit such a difference might have a more favorable profile. The recent report of a patient with a monoclonal IgA paraprotein targeting thrombin who did not have an associated severe bleeding phenotype suggests that it may be possible to target components of coagulation with a resultant antithrombotic effect but little if any bleeding effect. ${ }^{213}$ In this patient, the antibody bound to exosite 1 and not the active site of thrombin and so there may also be a kinetic basis for an apparent dissociation of effects.

It is important to understand the animal models used to evaluate new anticoagulants. For bleeding, the tail transection model $^{214}$ is frequently used in the preclinical evaluation of candidate antithrombotic molecules, but it is problematic because of the effect of vasoconstriction and that it is an open rather than a closed bleeding model. The saphenous vein bleeding model ${ }^{215}$ has been suggested as an alternative that may correlate more closely with clinical bleeding phenotype. ${ }^{216}$ Skin bleeding time is more suited for evaluating primary haemostasis (e.g. evaluating antiplatelet medication) but less suited for assessing effects of anticoagulants.

To assess effects on arterial thrombosis, ultrasound-induced plaque rupture in the APO-E KO mouse has been used as a preclinical model. ${ }^{217}$ The frequently used ferric chlorideinduced thrombosis model ${ }^{215}$ recreates a predictive and reproducible thrombus which can be subjected to inhibition by various drugs. This can be viewed as a screening procedure, selecting drugs only with potential inhibitory activity. However, this model does not indicate how a particular drug will work in humans or enable ranking of drugs.

\section{Recommendations from Theme 4}

- Study the role of lower affinity PAR4 thrombin receptor vis a vis PAR1 to establish whether PAR4 is a better target than PAR1, because PAR4 blockade causes less bleeding.

- Develop a practically feasible PFT that reflects in vivo platelet function and thrombus formation under physiologic conditions; standardize monitoring of $\mathrm{P}_{2} \mathrm{Y}_{12}$ inhibition; trials in high-risk patients, using clinically relevant physiological PFTs, should be performed to assess the relevance of PFT-based tailoring of therapy.
- Refine current risk scores in patients with $\mathrm{AF}$, in particular the decision to start anticoagulation in those with low scores; revise $\mathrm{CHA}_{2} \mathrm{DS}_{2}$-VASc score and the $\mathrm{ABC}$ score that includes biomarkers, also taking into account hypercoagulability markers; imaging studies may provide additional information in stroke risk.

- Organize regular follow-up of patients on NOAC treatment in a nurse-based manner involving anticoagulation clinics. Regional haemostasis centres can manage complex patients in a multidisciplinary manner.

- Develop separate risk scores for intracranial, GI, and uterine bleeding in patients on oral anticoagulants to improve risk prediction; this may also increase complexity.

- Develop, in those on NOACs, a sensitive test with short turnaround time and 24-hour availability for emergency situations; dose adjustment guided by laboratory assays may be appropriate in some circumstances; the 'therapeutic window' should be defined, to improve dose fine-tuning.

- Try to target components of coagulation with a resultant antithrombotic effect but little, if any, bleeding effect; optimize preclinical testing including a better choice in animal models, based on the model's characteristics related to thrombosis or bleeding.

\section{Pleiotropy of Coagulation Proteases, Thrombus Resolution, and Ischaemia- Reperfusion}

\section{Clot Resolution and Ischaemia-Reperfusion Injury}

Until recently, thrombectomy was considered an integral part of the treatment strategy for acute MI. Recent meta-analyses indicate that this is no longer tenable; only in case of heavy thrombus burden may thrombectomy be advantageous albeit at a potential cost of increased risk of stroke. ${ }^{218}$ For acute ischaemic stroke, however, the MR CLEAN study has shown that intra-arterial therapy, using for instance stent retrievers, significantly improved patient outcome and has since gained status of preferred treatment. ${ }^{219}$ Thrombectomy results in biobanks containing this material and allows analysis of this unique material to further our understanding of the thrombotic event and the processes involved in 'successful' thrombectomy and its sequelae. The following aspects deserve further attention:

Thrombus fragmentation and embolization. It was deemed important to develop new and relevant ways to phenotype the thrombus and determine its source, as current strategies seem inadequate. Furthermore, it was considered relevant to study the role of local fibrinolysis in embolization and fragmentation and the composition and disease state of the atherosclerotic vessel wall.

Stent-Thrombus interaction. We discussed which processes might play a role in the interaction between stent and thrombus; ${ }^{220}$ two issues were specified: the status of the local vasculature and of the coagulation system. With regards to the vasculature at the site of thrombectomy, TF content and the depth of injury were considered possible determinants of stent-thrombus interaction. Activation of the coagulation system was deemed equally important, considering that both 'erythrocyte-rich' and 'platelet-fibrin-rich' thrombi could 
grow fast, within minutes, while not reflecting thrombus age. Potentially, phenotyping based on the relative contribution of the different leukocyte subtypes adds relevant information.

Biobanking initiatives. There are many biobanking initiatives but not many specifically geared toward arterial thrombosis. Prerequisites for successful biobanks, aside from regular ethical considerations, were considered including (inter)national collaboration, thorough documentation of the clinical background of thrombus and patient; procedural aspects of thrombectomy; standardized and documented protocols for proper handling and storage of relevant materials.

\section{The Role of Activated Protein C in Limiting Brain Damage in Ischaemic Stroke}

Despite extensive efforts, no novel drug for ischaemic stroke therapy has been approved in the past decade. One promising drug candidate currently in phase II clinical studies for treatment of ischaemic stroke is the activated protein C (APC) variant 3K3A-APC. ${ }^{221}$ APC provides natural anticoagulant function by inactivating the coagulation cofactors Va and VIIIa. In addition, APC conveys direct effects on cells that involve multiple receptors including PAR1, PAR3, and the endothelial protein $C$ receptor (EPCR). ${ }^{222}$ Depending on the cell type and cell stress involved, these cellular activities of APC, collectively referred to as 'APC's cytoprotective activities', can be characterized as antiapoptotic and anti-inflammatory activity, beneficial alterations of gene expression profiles, protection of endothelial barrier function and regenerative activities.

Studies have shown beneficial effects of APC in rodent stroke models. $^{223}$ The use of molecularly engineered APC variants with altered selectivity profiles to rodent stroke models, such as the $3 \mathrm{~K} 3 \mathrm{~A}-\mathrm{APC}$ variant with minimal anticoagulant activity but normal cytoprotective activities, demonstrated that the beneficial effects of APC primarily require its cytoprotective activities but not its anticoagulant activities.

Recent insights into the molecular mechanisms for APC's cytoprotective activities identified noncanonical PAR1 and PAR3 activation by APC that give rise to novel tethered ligands capable of inducing biased cytoprotective signaling as a key distinction from the traditional canonical thrombin-mediated PAR1 and PAR3 signaling that generally results in prohaemostatic and proinflammatory effects. ${ }^{224}$ Based on the available data, the consensus model for APC's cytoprotective activities involves the binding of APC to the EPCR which permits APCmediated noncanonical activation of PAR1 at Arg46 and PAR3 at Arg41 resulting in the initiation of biased signaling and the corresponding cytoprotective effects. In addition, it has become clear that additional receptors including ApoER2, MAC1, PAR2, Tie2, factor $\mathrm{V}$, and protein $\mathrm{S}$ are involved to provide cell-typespecific variations to this model, but their integration into the overall precipitation of APC's cytoprotective activities remains incompletely understood.

Based on the new mechanistic insights, the following research avenues were identified:

1. To determine the effects of anticoagulant drugs on the endogenous protein $C$ system and in particular the ability of the endogenous cytoprotective protein $C$ pathway to continue to provide beneficial effects on cells and tissues. The (patho)physiological generation of APC by thrombin/ thrombomodulin may be affected by anticoagulant drugs that aim to limit thrombin generation. With the increasing use of direct oral anticoagulants (NOACs), questions arise if and how these drugs affect normal APC generation and the ability of APC to provide normal cytoprotective effects. Protein $C$ is also sensitive to VKAs as it contains a GLA domain that is involved in binding of negatively charged phospholipid vesicles required for APC's anticoagulant activity, binding to EPCR required for efficient protein C activation and APC's cytoprotective effects on cells. Thus, questions arise how potential effects of NOACs compare with VKA for protein C activation and APC's cytoprotective effects.

2. There is an urgent need for the development of tools, assays, and the identification of biomarkers to evaluate the endogenous cytoprotective protein $C$ pathway in patient samples. Assays and tools are available for analysis of the anticoagulant protein $C$ pathway, but these cannot be readily extrapolated to analysis of the cytoprotective protein $C$ pathway.

3. Basic research is needed to advance our understanding of the molecular mechanisms responsible for APC's cytoprotective activities. With the notion that APC induces noncanonical activation of PAR1 and PAR3, biased signaling, and the integration of PAR signaling based on homo- and hetero-dimer formation, the realm of possibilities for specialized signaling variations has grown exponentially.

\section{New Concept of Thrombolysis and How to Improve Clot Lysis in Ischaemic Stroke}

The clinical manifestations of ischaemic stroke are heterogeneous and successful treatment depends on many variables involved in thrombus formation such as physical location in the brain, time from onset, and patient-specific variables (age, gender, comorbidities, etc.). The standard of care for acute ischaemic stroke now involves IV alteplase (recombinant tissue-type plasminogen activator [tPA]) within 4.5 hours, followed by antiplatelet treatment (acetylsalicylic acid or clopidogrel) 24 hours after infusion of thrombolytics, to avoid excess risk of intracerebral haemorrhage. ${ }^{225,226}$ The major goal of thrombolytic treatment is to rapidly establish oxygenated blood flow to limit brain damage. This can be achieved with thrombolytic drugs, such as tPA, or by mechanical interventions such as endovascular thrombectomy. Mechanical thrombectomy by means of retrievable stents has been proven a very effective treatment for acute ischaemic stroke caused by large artery thromboembolic occlusion ${ }^{219,227-229}$ and is now accepted as standard treatment, 230,231 and incorporated in major guidelines. ${ }^{232,233}$ Regarding the use of thrombolytic drugs, the MR CLEAN initiative reported that clots could only be lysed in one-third of the patients who were treated with recombinant tPA. ${ }^{219}$ This relatively low success rate has been partly attributed to the fact that tPA only accomplishes its thrombolytic effect in small clots because the core of the thrombus can be reached. ${ }^{234}$ Infusion during a longer period of time 
might improve the impact of tPA; however, it may increase the risk of massive brain damage caused by bleeding. Meanwhile, proper reperfusion of the brain after endovascular thrombectomy that is usually performed on patients with large thrombi is often not achieved, for unknown reasons. It has been suggested that the formation/release of microthrombi that may diminish downstream microvascular perfusion may play a role. ${ }^{235,236}$ Nonetheless, reperfusion can be visualized and analysed only in the larger vessels. These uncertainties and side effects of current treatments for ischaemic stroke highlight the importance of improving drug treatment. The ideal treatment should comprise drugs that have immediate effects to minimize brain damage, to safely enhance fibrinolysis, and simultaneously do not cause bleeding. This kind of treatment could be combined with thrombectomy resulting in fast mechanical removal of most of the thrombus and fibrinolytic removal of microthrombi.

One novel research avenue is directed at the interaction between vWF and glycoprotein $1 \mathrm{~b}$, and another approach is to infuse ADAMTS13, and both approaches appear to reduce clot stability in models of ischaemic stroke. ${ }^{237,238}$

Another concept of safe thrombolysis combines profibrinolytic approaches such as anti-PAI-1, anti-thrombin activatable fibrinolysis inhibitor (anti-TAFI), and anti- $\alpha_{2}-$ antiplasmin. ${ }^{239}$ One promising strategy, for which the proof of concept has been demonstrated in mouse models, is based on a bispecific diabody against TAFI and PAI- $1 .{ }^{240}$ It simultaneously blocks the two antifibrinolytic proteins resulting in a significantly enhanced activity of endogenous t-PA. Compared with a monoclonal antibody (150 kDa), it is much smaller ( $50 \mathrm{kDa}$ ) and thus might be able to reach the core of the thrombus more easily. Additionally, it has a half-life of approximately 120 minutes instead of 2 to 3 weeks compared with monoclonal antibodies. Therefore, the diabody might be beneficial as a safe fibrinolytic with a reduced bleeding risk. Additionally, the possibilities of combining other fibrinolytics, such as anti- $\alpha_{2}$-antiplasmin, with PAI- 1 or TAFI still needs to be investigated, as well as combining such profibrinolytics with thrombectomy. When designing a factorial 'cocktail' study, the challenge is to determine the right doses (beneficial effect with minimal harmful side effects) of the right combination treatments.

\section{Recommendations from Theme 5}

- Organize structured, focused biobanking initiatives to support relevant ways of thrombus phenotyping; develop studies to identify vessel wall-stent coagulation/fibrinolysis interactions.

- Determine the effects of anticoagulant drugs on the endogenous protein $\mathrm{C}$ system including its cytoprotective effects on cells and tissues; new tools needed to evaluate the endogenous cytoprotective protein $C$ pathway in patient samples; basic research to advance our understanding of the mechanisms of APC's cytoprotective activities.

- Improve drug treatment as well as management of patients suffering from ischaemic stroke; the possibilities of combining fibrinolytics, such as anti- $\alpha_{2}$-antiplasmin, with PAI-1 or TAFI needs to be investigated, as well as combining such profibrinolytics with thrombectomy.

\section{What is known about this topic?}

- Atherothrombosis occurs secondary to atherosclerosis, a chronic inflammatory vascular disease.

- Detailed information on individual risk profiles contributing to atherothrombosis is lacking.

- Recent insights in the diversity and functionality of monocytes (macrophages), leukocytes, and platelets in driving atherosclerosis and subsequent thrombosis have become available.

- This knowledge is poorly implemented in research on atherothrombosis.

- The contact system, factors XI and XIII, and fibrinogen/ fibrin are key players in determining net coagulation activity.

- Recent insights suggest important interactions with platelets, as well as inflammatory mechanisms that link these systems.

- New avenues of antithrombotic management are emerging, but these require refinement or tailoring.

- Improved knowledge of PAR-1 and PAR-4 signalling on pathways creates opportunities for better tailored therapy.

- Tailoring antiplatelet therapy based on platelet function assays is currently not yet feasible.

- Anticoagulation in patients with atrial fibrillation and relatively low-risk scores is still unsettled.

- Bleeding risk scores may vary for different organ systems.

- Long-term anticoagulant management, specifically with direct oral anticoagulants (DOACs), requires better organization.

- Laboratory testing of DOAC is required under specific conditions.

- Studies on thrombus properties are limited because of poor quality and number of biobanking facilities.

- Activated protein $C$ mutants are increasingly interesting for their cytoprotective properties (e.g. in the management of patients with ischaemic stroke).

- Management of patients with ischaemic stroke merits further refinement based on promising outcomes of studies aimed at timely clot removal.

- New developments in the field of improved clot lysis are being explored, but the clinical impact has not been addressed yet.

\section{What does this paper add?}

- Specific risk factors like ectopic fat need to be considered.

- Proteomic and metabolomics data should be added to genetic information.

- Better definitions of plaque stability contribution to atherothrombosis are needed. 
- Mechanisms of leukocyte and macrophage plasticity, migration and transformation in murine atherosclerosis need to be considered.

- Disease mechanism-based biomarkers need to be identified.

- Develop experimental systems that incorporate whole blood flow to understand how RBCs influence thrombus formation and stability.

- Knowledge on platelet heterogeneity and priming conditions needs to be translated toward the in vivo situation.

- The role of factor XI in thrombosis including the lower margins of this factor related to safe and effective antithrombotic therapy needs to be established.

- Factor XI is a key regulator in linking platelets, thrombin generation and inflammatory mechanisms in a reninangiotensin-dependent manner; the impact on thrombin-dependent PAR signaling needs further study.

- The fundamental mechanisms in FXIII biology and biochemistry and its impact on thrombus biophysical characteristics need to be explored.

- The interactions of red cells and fibrin formation and its consequences for thrombus formation and lysis need to be addressed.

- Platelet-fibrin interactions are pivotal determinants of clot formation and stability with potential therapeutic consequences.

- The role of PAR-4 vis a vis PAR-1 as target for antithrombotic therapy merits study.

- Ongoing trials on platelet function test-based antiplatelet therapy adjustment may support development of practically feasible tests

- Risk scores for patients with AF need refinement, taking new biomarkers including for coagulation into account.

- Risk scores that consider organ system differences in bleeding may have added value.

- NOAC treatment requires better organization, including education and emergency access; laboratory testing still needs rapidly available sensitive tests with short turnaround time.

- Biobanks specifically for thrombus storage and analysis are needed.

- Further studies on novel modified activated protein Cbased agents are required including its cytoprotective properties.

- New avenues for optimizing treatment of patients with ischaemic stroke are needed, also including novel agents that modify fibrinolytic activity (aimed at PAI-1 and TAFI) currently studies in subjects with pulmonary embolism.

Conflict of Interest

None declared.

\section{Acknowledgements}

Mrs. Lidewij Bos, Department of Biochemistry at CARIM, is gratefully acknowledged for logistic and editorial support.

\section{References}

1 Ross R. Atherosclerosis-an inflammatory disease. N Engl J Med 1999;340(02):115-126

2 Ylä-Herttuala S, Bentzon JF, Daemen M, et al. Stabilisation of atherosclerotic plaques. Position paper of the European Society of Cardiology (ESC) Working Group on atherosclerosis and vascular biology. Thromb Haemost 2011;106(01):1-19

3 Engelmann B, Massberg S. Thrombosis as an intravascular effector of innate immunity. Nat Rev Immunol 2013;13(01):34-45

4 Levi M, van der Poll T, Büller HR. Bidirectional relation between inflammation and coagulation. Circulation 2004;109:2698-2704

5 Borissoff JI, Spronk HM, ten Cate H. The hemostatic system as a modulator of atherosclerosis. N Engl J Med 2011;364(18): 1746-1760

6 Williams EP, Mesidor M, Winters K, Dubbert PM, Wyatt SB. Overweight and obesity: prevalence, consequences, and causes of a growing public health problem. Curr Obes Rep 2015;4(03): 363-370

7 Denis GV, Obin MS. 'Metabolically healthy obesity': origins and implications. Mol Aspects Med 2013;34(01):59-70

8 Morelli M, Gaggini M, Daniele G, Marraccini P, Sicari R, Gastaldelli A. Ectopic fat: the true culprit linking obesity and cardiovascular disease? Thromb Haemost 2013;110(04):651-660

9 Thanassoulis G, Massaro JM, O'Donnell CJ, et al. Pericardial fat is associated with prevalent atrial fibrillation: the Framingham Heart Study. Circ Arrhythm Electrophysiol 2010;3:345-350

10 Iacobellis G, Zaki MC, Garcia D, Willens HJ. Epicardial fat in atrial fibrillation and heart failure. Horm Metab Res 2014;46(08): 587-590

11 Lim S, Meigs JB. Links between ectopic fat and vascular disease in humans. Arterioscler Thromb Vasc Biol 2014;34(09):1820-1826

12 Balistreri CR, Caruso C, Candore G. The role of adipose tissue and adipokines in obesity-related inflammatory diseases. Mediators Inflamm 2010;2010(10):802078

13 Badimon L, Hernández Vera R, Vilahur G. Atherothrombotic risk in obesity. Hamostaseologie 2013;33(04):259-268

14 Silver HJ, Welch EB, Avison MJ, Niswender KD. Imaging body composition in obesity and weight loss: challenges and opportunities. Diabetes Metab Syndr Obes 2010;3:337-347

15 Seabolt LA, Welch EB, Silver HJ. Imaging methods for analyzing body composition in human obesity and cardiometabolic disease. Ann N Y Acad Sci 2015;1353:41-59

16 Kessler T, Vilne B, Schunkert H. The impact of genome-wide association studies on the pathophysiology and therapy of cardiovascular disease. EMBO Mol Med 2016;8(07):688-701

17 Thanassoulis G, Peloso GM, Pencina MJ, et al; Circ Cardiovasc Genet American Heart Association. A genetic risk score is associated with incident cardiovascular disease and coronary artery calcium: the Framingham Heart Study. Circ Cardiovasc Genet 2012;5(01):113-121

18 Hindieh W, Pilote L, Cheema A, et al; PRAXY Investigators*. Association between family history, a genetic risk score, and severity of coronary artery disease in patients with premature acute coronary syndromes. Arterioscler Thromb Vasc Biol 2016; 36(06):1286-1292

19 Piepoli MF, Hoes AW, Agewall S, et al; Authors/Task Force Members. 2016 European Guidelines on cardiovascular disease prevention in clinical practice: The Sixth Joint Task Force of the European Society of Cardiology and Other Societies on Cardiovascular Disease Prevention in Clinical Practice (constituted by representatives of 10 societies and by invited experts)Developed 
with the special contribution of the European Association for Cardiovascular Prevention \& Rehabilitation (EACPR). Eur Heart J 2016;37(29):2315-2381

20 Stone GW, Maehara A, Lansky AJ, et al; PROSPECT Investigators. A prospective natural-history study of coronary atherosclerosis. N Engl J Med 2011;364(03):226-235

21 Galis ZS, Sukhova GK, Lark MW, Libby P. Increased expression of matrix metalloproteinases and matrix degrading activity in vulnerable regions of human atherosclerotic plaques. J Clin Invest 1994;94(06):2493-2503

22 Zheng B, Mintz GS, McPherson JA, et al. Predictors of plaque rupture within nonculprit fibroatheromas in patients with acute coronary syndromes: the PROSPECT Study. JACC Cardiovasc Imaging 2015;8(10):1180-1187

23 Tearney GJ, Regar E, Akasaka T, et al; International Working Group for Intravascular Optical Coherence Tomography (IWG-IVOCT). Consensus standards for acquisition, measurement, and reporting of intravascular optical coherence tomography studies: a report from the International Working Group for Intravascular Optical Coherence Tomography Standardization and Validation. J Am Coll Cardiol 2012;59(12): 1058-1072

24 Ruparelia N, Chai JT, Fisher EA, Choudhury RP. Inflammatory processes in cardiovascular disease: a route to targeted therapies. Nat Rev Cardiol 2017;14(03):133-144

25 Hermann S, Starsichova A, Waschkau B, et al. Non-FDG imaging of atherosclerosis: will imaging of MMPs assess plaque vulnerability? J Nucl Cardiol 2012;19(03):609-617

26 Fujimoto S, Hartung D, Ohshima S, et al. Molecular imaging of matrix metalloproteinase in atherosclerotic lesions: resolution with dietary modification and statin therapy. J Am Coll Cardiol 2008;52(23):1847-1857

27 Ughi GJ, Wang H, Gerbaud E, et al. Clinical characterization of coronary atherosclerosis with dual-modality OCT and nearinfrared autofluorescence imaging. JACC Cardiovasc Imaging 2016;9(11):1304-1314

28 Naghavi M, Libby P, Falk E, et al; Circulation American Heart Association. From vulnerable plaque to vulnerable patient: a call for new definitions and risk assessment strategies: Part I. Circulation 2003;108(14):1664-1672

29 Rittersma SZ, van der Wal AC, Koch KT, et al; Circulation American Heart Association. Plaque instability frequently occurs days or weeks before occlusive coronary thrombosis: a pathological thrombectomy study in primary percutaneous coronary intervention. Circulation 2005;111(09):11601165

30 Kramer MC, van der Wal AC, Koch KT, et al; Circulation American Heart Association. Presence of older thrombus is an independent predictor of long-term mortality in patients with ST-elevation myocardial infarction treated with thrombus aspiration during primary percutaneous coronary intervention. Circulation 2008; 118(18):1810-1816

31 Lowe G, Rumley A. The relevance of coagulation in cardiovascular disease: what do the biomarkers tell us? Thromb Haemost 2014; 112(05):860-867

32 Ankrom W, Wood HB, Xu J, et al. Preclinical and translational evaluation of coagulation factor IXa as a novel therapeutic target. Pharmacol Res Perspect 2016;4(01):e00207

33 Smith FB, Lee AJ, Fowkes FG, Price JF, Rumley A, Lowe GD. Hemostatic factors as predictors of ischemic heart disease and stroke in the Edinburgh Artery Study. Arterioscler Thromb Vasc Biol 1997;17(11):3321-3325

34 Barber M, Langhorne P, Rumley A, et al. D-dimer predicts early clinical progression in ischemic stroke: confirmation using routine clinical assays. Stroke 2006;37:1113-1115

35 Hijazi Z, Oldgren J, Siegbahn A, Granger CB, Wallentin L. Biomarkers in atrial fibrillation: a clinical review. Eur Heart J 2013; 34(20):1475-1480
36 Nozawa T, Inoue $\mathrm{H}$, Hirai T, et al. D-dimer level influences thromboembolic events in patients with atrial fibrillation. Int J Cardiol 2006;109(01):59-65

37 Ridger VC, Boulanger CM, Angelillo-Scherrer A, et al; Position Paper of the European Society of Cardiology (ESC) Working Group on Atherosclerosis and Vascular Biology. Microvesicles in vascular homeostasis and diseases. Thromb Haemost 2017; 117(07):1296-1316

38 Tsiantoulas D, Diehl CJ, Witztum JL, et al. B cells and humoral immunity in atherosclerosis. Circ Res 2014;114:1743-1756

39 Tsiantoulas D, Sage AP, Mallat Z, et al. Targeting B cells in atherosclerosis: closing the gap from bench to bedside. Arterioscler Thromb Vasc Biol 2015;35:296-302

40 Sun J, Sukhova GK, Wolters PJ, et al. Mast cells promote atherosclerosis by releasing proinflammatory cytokines. Nat Med 2007;13(06):719-724

41 Drechsler M, Megens RTA, van Zandvoort M, et al. Hyperlipidemia-triggered neutrophilia promotes early atherosclerosis. Circulation 2010;122:1837-1845

42 Libby P, Nahrendorf M, Swirski FK. Monocyte heterogeneity in cardiovascular disease. Semin Immunopathol 2013;35(05): 553-562

43 Ye Y-X, Calcagno C, Binderup T, et al. Imaging macrophage and hematopoietic progenitor proliferation in atherosclerosis. Circ Res 2015;117(10):835-845

44 McArdle S, Mikulski Z, Ley K. Live cell imaging to understand monocyte, macrophage, and dendritic cell function in atherosclerosis. J Exp Med 2016;213(07):1117-1131

45 Ingersoll MA, Platt AM, Potteaux S, Randolph GJ. Monocyte trafficking in acute and chronic inflammation. Trends Immunol 2011;32(10):470-477

46 Robbins CS, Hilgendorf I, Weber GF, et al. Local proliferation dominates lesional macrophage accumulation in atherosclerosis. Nat Med 2013;19(09):1166-1172

47 Feil S, Fehrenbacher B, Lukowski R, et al. Transdifferentiation of vascular smooth muscle cells to macrophage-like cells during atherogenesis. Circ Res 2014;115(07):662-667

48 Allahverdian S, Chehroudi AC, McManus BM, Abraham T, Francis GA; Circulation American Heart Association. Contribution of intimal smooth muscle cells to cholesterol accumulation and macrophage-like cells in human atherosclerosis. Circulation 2014;129(15):1551-1559

49 von Brühl ML, Stark K, Steinhart A, et al. Monocytes, neutrophils, and platelets cooperate to initiate and propagate venous thrombosis in mice in vivo. J Exp Med 2012;209(04):819-835

50 Subramaniam S, Jurk K, Hobohm L, et al. Distinct contributions of complement factors to platelet activation and fibrin formation in venous thrombus development. Blood 2017;129(16):2291-2302

51 Langer F, Spath B, Fischer C, et al. Rapid activation of monocyte tissue factor by antithymocyte globulin is dependent on complement and protein disulfide isomerase. Blood 2013;121(12): 2324-2335

52 Rothmeier AS, Marchese P, Langer F, et al. Tissue factor prothrombotic activity is regulated by integrin-arf6 trafficking. Arterioscler Thromb Vasc Biol 2017;37:1323-1331

53 Di Minno MN, Iervolino S, Peluso R, Scarpa R, Di Minno G. TNF- $\alpha$ blockers and carotid intima-media thickness: an emerging issue in the treatment of psoriatic arthritis. Intern Emerg Med 2012;7 (Suppl 2):S97-S98

54 Ridker PM, Everett BM, Thuren T, et al; CANTOS Trial Group. Antiinflammatory therapy with canakinumab for atherosclerotic disease. N Engl J Med 2017;377(12):1119-1131

55 Furlan-Freguia C, Marchese P, Gruber A, Ruggeri ZM, Ruf W. P2 $\times 7$ receptor signaling contributes to tissue factor-dependent thrombosis in mice. J Clin Invest 2011;121(07):2932-2944

56 Rothmeier AS, Marchese P, Petrich BG, et al. Caspase-1-mediated pathway promotes generation of thromboinflammatory microparticles. J Clin Invest 2015;125(04):1471-1484 
57 Piscopiello M, Sessa M, Anzalone N, et al. P2 $\times 7$ receptor is expressed in human vessels and might play a role in atherosclerosis. Int J Cardiol 2013;168(03):2863-2866

58 Borissoff JI, Otten JJ, Heeneman S, et al. Genetic and pharmacological modifications of thrombin formation in apolipoprotein e-deficient mice determine atherosclerosis severity and atherothrombosis onset in a neutrophil-dependent manner. PLoS One 2013;8(02):e55784

59 Gautier EL, Shay T, Miller J, et al; Immunological Genome Consortium. Gene-expression profiles and transcriptional regulatory pathways that underlie the identity and diversity of mouse tissue macrophages. Nat Immunol 2012;13(11):1118-1128

60 Chapman HA Jr, Allen CL, Stone OL, Fair DS. Human alveolar macrophages synthesize factor VII in vitro. Possible role in interstitial lung disease. J Clin Invest 1985;75(06):2030-2037

61 Schaffner F, Yokota N, Carneiro-Lobo T, et al. Endothelial protein $C$ receptor function in murine and human breast cancer development. PLoS One 2013;8(04):e61071

62 Nhu QM, Shirey KA, Pennini ME, Stiltz J, Vogel SN. Proteinaseactivated receptor 2 activation promotes an anti-inflammatory and alternatively activated phenotype in LPS-stimulated murine macrophages. Innate Immun 2012;18(02):193-203

63 Badeanlou L, Furlan-Freguia C, Yang G, Ruf W, Samad F. Tissue factor-protease-activated receptor 2 signaling promotes dietinduced obesity and adipose inflammation. Nat Med 2011;17 (11):1490-1497

64 Byrnes JR, Wolberg AS. Red blood cells in thrombosis. Blood 2017;130(16):1795-1799

65 Kuypers FA, Lewis RA, Hua M, et al. Detection of altered membrane phospholipid asymmetry in subpopulations of human red blood cells using fluorescently labeled annexin V. Blood 1996;87 (03):1179-1187

66 Fogelson AL, Neeves KB. Fluid mechanics of blood clot formation. Annu Rev Fluid Mech 2015;47:377-403

67 Grabowski EF, Yam K, Gerace M. Evaluation of hemostasis in flowing blood. Am J Hematol 2012;87(01, Suppl 1):S51-S55

68 Lowe GD, Lee AJ, Rumley A, Price JF, Fowkes FG. Blood viscosity and risk of cardiovascular events: the Edinburgh Artery Study. $\mathrm{Br}$ J Haematol 1997;96(01):168-173

69 Horne MK III, Cullinane AM, Merryman PK, Hoddeson EK. The effect of red blood cells on thrombin generation. $\mathrm{Br} \mathrm{J}$ Haematol 2006;133(04):403-408

70 Ninivaggi M, Apitz-Castro R, Dargaud Y, de Laat B, Hemker HC, Lindhout $\mathrm{T}$. Whole-blood thrombin generation monitored with a calibrated automated thrombogram-based assay. Clin Chem 2012;58(08):1252-1259

71 Peyrou V, Lormeau JC, Hérault JP, Gaich C, Pfliegger AM, Herbert JM. Contribution of erythrocytes to thrombin generation in whole blood. Thromb Haemost 1999;81(03):400-406

72 Rubin O, Delobel J, Prudent M, et al. Red blood cell-derived microparticles isolated from blood units initiate and propagate thrombin generation. Transfusion 2013;53(08):1744-1754

73 Whelihan MF, Zachary V, Orfeo T, Mann KG. Prothrombin activation in blood coagulation: the erythrocyte contribution to thrombin generation. Blood 2012;120(18):3837-3845

74 Cines DB, Lebedeva T, Nagaswami C, et al. Clot contraction: compression of erythrocytes into tightly packed polyhedra and redistribution of platelets and fibrin. Blood 2014;123(10):1596-1603

75 Heemskerk JW, Mattheij NJ, Cosemans JM. Platelet-based coagulation: different populations, different functions. J Thromb Haemost 2013;11(01):2-16

76 Baaten CC, Veenstra LF, Wetzels R, et al. Gradual increase in thrombogenicity of juvenile platelets formed upon offset of prasugrel medication. Haematologica 2015;100(09):1131-1138

77 Eckly A, Rinckel J-Y, Proamer F, et al. Respective contributions of single and compound granule fusion to secretion by activated platelets. Blood 2016;128(21):2538-2549
78 Richardson JL, Shivdasani RA, Boers C, Hartwig JH, Italiano JE Jr. Mechanisms of organelle transport and capture along proplatelets during platelet production. Blood 2005;106(13):4066-4075

79 Moreau T, Evans AL, Vasquez L, et al. Large-scale production of megakaryocytes from human pluripotent stem cells by chemically defined forward programming. Nat Commun 2016;7:11208

80 Blair TA, Moore SF, Hers I. Circulating primers enhance platelet function and induce resistance to antiplatelet therapy. J Thromb Haemost 2015;13(08):1479-1493

81 Baaten CC, Ten Cate H, van der Meijden PE, Heemskerk JW. Platelet populations and priming in hematological diseases. Blood Rev 2017;31(06):389-399

82 Stalker TJ, Welsh JD, Tomaiuolo M, et al. A systems approach to hemostasis: 3 . Thrombus consolidation regulates intrathrombus solute transport and local thrombin activity. Blood 2014;124 (11):1824-1831

83 Gailani D, Broze GJ Jr. Factor XI activation in a revised model of blood coagulation. Science 1991;253(5022):909-912

84 Büller HR, Bethune C, Bhanot S, et al; FXI-ASO TKA Investigators. Factor XI antisense oligonucleotide for prevention of venous thrombosis. N Engl J Med 2015;372(03):232-240

85 Drake TA, Morrissey JH, Edgington TS. Selective cellular expression of tissue factor in human tissues. Implications for disorders of hemostasis and thrombosis. Am J Pathol 1989;134(05):1087-1097

86 van Montfoort ML, Meijers JC. Anticoagulation beyond direct thrombin and factor Xa inhibitors: indications for targeting the intrinsic pathway? Thromb Haemost 2013;110(02):223-232

87 Bane CE Jr, Ivanov I, Matafonov A, et al. Factor XI deficiency alters the cytokine response and activation of contact proteases during polymicrobial sepsis in mice. PLoS One 2016;11(04):e0152968

88 Shnerb Ganor R, Harats D, Schiby G, et al. Factor XI deficiency protects against atherogenesis in apolipoprotein $\mathrm{E} /$ factor $\mathrm{XI}$ double knockout mice. Arterioscler Thromb Vasc Biol 2016;36 (03):475-481

89 Preis M, Hirsch J, Kotler A, et al. Factor XI deficiency is associated with lower risk for cardiovascular and venous thromboembolism events. Blood 2017;129(09):1210-1215

90 Kossmann S, Lagrange J, Jäckel S, et al. Platelet-localized FXI promotes a vascular coagulation-inflammatory circuit in arterial hypertension. Sci Transl Med 2017 Feb 1;9(375). pii:eaah4923

91 Connolly SJ, Ezekowitz MD, Yusuf S, et al; RE-LY Steering Committee and Investigators. Dabigatran versus warfarin in patients with atrial fibrillation. N Engl J Med 2009;361(12):1139-1151

92 Al-Horani RA, Desai UR. Factor XIa inhibitors: a review of the patent literature. Expert Opin Ther Pat 2016;26(03):323-345

93 Crooke ST, Baker BF, Witztum JL, et al. The effects of 2'-Omethoxyethyl containing antisense oligonucleotides on platelets in human clinical trials. Nucleic Acid Ther 2017;27(03):121-129

94 Wild PS, Zeller T, Beutel M, et al. The Gutenberg Health Study. Bundesgesundheitsblatt Gesundheitsforschung Gesundheitsschutz 2012;55:824-829

95 Morrissey JH, Smith SA. Polyphosphate as modulator of hemostasis, thrombosis, and inflammation. J Thromb Haemost 2015;13 (Suppl 1):S92-S97

96 Müller F, Gailani D, Renné T. Factor XI and XII as antithrombotic targets. Curr Opin Hematol 2011;18(05):349-355

$97 \mathrm{Wu}$ Y. Contact pathway of coagulation and inflammation. Thromb J 2015;13:17

98 Weidmann H, Heikaus L, Long AT, Naudin C, Schlüter H, Renné T. The plasma contact system, a protease cascade at the nexus of inflammation, coagulation and immunity. Biochim Biophys Acta 2017;1864(11, Pt B):2118-2127

99 Mutch NJ. Emerging roles for factor XII in vivo.J Thromb Haemost 2011;9(07):1355-1358

100 Nickel KF, Long AT, Fuchs TA, et al. Factor XII as a therapeutic target in thromboembolic and inflammatory diseases. Arterioscler Thromb Vasc Biol 2017;37:13-20 
101 Renné T. The vascular side of plasma kallikrein. Blood 2015;125 (04):589-590

102 Björkqvist J, Jämsä A, Renné T. Plasma kallikrein: the bradykininproducing enzyme. Thromb Haemost 2013;110(03):399-407

103 Longhurst H, Cicardi M, Craig T, et al; COMPACT Investigators. Prevention of hereditary angioedema attacks with a subcutaneous C1 inhibitor. N Engl J Med 2017;376(12):1131-1140

104 Merkulov S, Zhang WM, Komar AA, et al. Deletion of murine kininogen gene 1 (mKng1) causes loss of plasma kininogen and delays thrombosis. Blood 2008;111(03):1274-1281

105 Banerji A, Busse P, Shennak M, et al. Inhibiting plasma kallikrein for hereditary angioedema prophylaxis. N Engl J Med 2017;376 (08):717-728

106 Langhauser F, Göb E, Kraft P, et al. Kininogen deficiency protects from ischemic neurodegeneration in mice by reducing thrombosis, blood-brain barrier damage, and inflammation. Blood 2012;120(19):4082-4092

107 Labberton L, Kenne E, Long AT, et al. Neutralizing blood-borne polyphosphate in vivo provides safe thromboprotection. Nat Commun 2016;7:12616

108 Muszbek L, Yee VC, Hevessy Z. Blood coagulation factor XIII: structure and function. Thromb Res 1999;94(05):271-305

109 Bagoly Z, Koncz Z, Hársfalvi J, Muszbek L. Factor XIII, clot structure, thrombosis. Thromb Res 2012;129(03):382-387

110 Bereczky Z, Muszbek L. Factor XIII and venous thromboembolism. Semin Thromb Hemost 2011;37(03):305-314

111 Ariëns RA, Lai T-S, Weisel JW, Greenberg CS, Grant PJ. Role of factor XIII in fibrin clot formation and effects of genetic polymorphisms. Blood 2002;100(03):743-754

112 Ariëns RA, Philippou H, Nagaswami C, Weisel JW, Lane DA, Grant PJ. The factor XIII V34L polymorphism accelerates thrombin activation of factor XIII and affects cross-linked fibrin structure. Blood 2000;96(03):988-995

113 Aleman MM, Byrnes JR, Wang J-G, et al. Factor XIII activity mediates red blood cell retention in venous thrombi. J Clin Invest 2014;124(08):3590-3600

114 Hur WS, Mazinani N, Lu XJ, et al. Coagulation factor XIIla is inactivated by plasmin. Blood 2015;126(20):2329-2337

115 Mammadova-Bach E, Ollivier V, Loyau S, et al. Platelet glycoprotein VI binds to polymerized fibrin and promotes thrombin generation. Blood 2015;126(05):683-691

116 Alshehri OM, Hughes CE, Montague S, et al. Fibrin activates GPVI in human and mouse platelets. Blood 2015;126(13): $1601-1608$

117 Stalker TJ, Traxler EA, Wu J, et al. Hierarchical organization in the hemostatic response and its relationship to the platelet-signaling network. Blood 2013;121(10):1875-1885

118 Allan P, Uitte de Willige S, Abou-Saleh RH, Connell SD, Ariëns RA. Evidence that fibrinogen $\gamma^{\prime}$ directly interferes with protofibril growth: implications for fibrin structure and clot stiffness. J Thromb Haemost 2012;10(06):1072-1080

119 Trégouët D-A, Heath S, Saut N, et al. Common susceptibility alleles are unlikely to contribute as strongly as the FV and ABO loci to VTE risk: results from a GWAS approach. Blood 2009;113 (21):5298-5303

120 Miszta A, Pelkmans L, Lindhout T, et al. Thrombin-dependent Incorporation of von Willebrand Factor into a Fibrin Network. J Biol Chem 2014;289(52):35979-35986

121 Wang Y, Reheman A, Spring CM, et al. Plasma fibronectin supports hemostasis and regulates thrombosis. J Clin Invest 2014;124(10):4281-4293

122 Byrnes JR, Wilson C, Boutelle AM, et al. The interaction between fibrinogen and zymogen FXIII-A2B2 is mediated by fibrinogen residues $\gamma 390-396$ and the FXIII-B subunits. Blood 2016;128 (15):1969-1978

123 Smith KA, Adamson PJ, Pease RJ, et al. Interactions between factor XIII and the alphaC region of fibrinogen. Blood 2011;117 (12):3460-3468
124 Sakata Y, Aoki N. Significance of cross-linking of alpha 2-plasmin inhibitor to fibrin in inhibition of fibrinolysis and in hemostasis. J Clin Invest 1982;69(03):536-542

125 Whyte CS, Swieringa F, Mastenbroek TG, et al. Plasminogen associates with phosphatidylserine-exposing platelets and contributes to thrombus lysis under flow. Blood 2015;125(16): 2568-2578

126 Mitchell JL, Lionikiene AS, Fraser SR, Whyte CS, Booth NA, Mutch NJ. Functional factor XIII-A is exposed on the stimulated platelet surface. Blood 2014;124(26):3982-3990

127 Carvalho FA, Connell S, Miltenberger-Miltenyi G, et al. Atomic force microscopy-based molecular recognition of a fibrinogen receptor on human erythrocytes. ACS Nano 2010;4(08):4609-4620

128 Guedes AF, Carvalho FA, Malho I, Lousada N, Sargento L, Santos NC. Atomic force microscopy as a tool to evaluate the risk of cardiovascular diseases in patients. Nat Nanotechnol 2016;11 (08):687-692

129 Du VX, van Os G, Kremer Hovinga JA, et al. Indications for a protective function of beta2-glycoprotein I in thrombotic thrombocytopenic purpura. Br J Haematol 2012;159(01):94-103

130 Bloemen S, Wu XX, Devreese KM, de Laat B, Rand JH, Vasovic LV. Inverted erythrocyte membranes demonstrate $\beta 2 \mathrm{GPI}$-antiphospholipid antibody interactions and membrane crosslinking. Thromb Res 2016;146:89-94

131 Fuchs TA, Brill A, Duerschmied D, et al. Extracellular DNA traps promote thrombosis. Proc Natl Acad Sci U S A 2010;107(36): 15880-15885

132 Varjú I, Longstaff C, Szabó L, et al. DNA, histones and neutrophil extracellular traps exert anti-fibrinolytic effects in a plasma environment. Thromb Haemost 2015;113(06):1289-1298

133 Bagoly Z, Haramura G, Muszbek L. Down-regulation of activated factor XIII by polymorphonuclear granulocyte proteases within fibrin clot. Thromb Haemost 2007;98(02):359-367

134 Sidelmann JJ, Gram J, Jespersen J, Kluft C. Fibrin clot formation and lysis: basic mechanisms. Semin Thromb Hemost 2000;26 (06):605-618

135 Tricoci P, Huang Z, Held C, et al; TRACER Investigators. Thrombinreceptor antagonist vorapaxar in acute coronary syndromes. N Engl J Med 2012;366(01):20-33

136 Morrow DA, Braunwald E, Bonaca MP, et al; TRA 2P-TIMI 50 Steering Committee and Investigators. Vorapaxar in the secondary prevention of atherothrombotic events. N Engl J Med 2012;366(15):1404-1413

137 Scirica BM, Bonaca MP, Braunwald E, et al; TRA 2 P-TIMI 50 Steering Committee Investigators. Vorapaxar for secondary prevention of thrombotic events for patients with previous myocardial infarction: a prespecified subgroup analysis of the TRA 2 P-TIMI 50 trial. Lancet 2012;380(9850):1317-1324

138 Niclou SP, Suidan HS, Pavlik A, Vejsada R, Monard D. Changes in the expression of protease-activated receptor 1 and protease nexin-1 mRNA during rat nervous system development and after nerve lesion. Eur J Neurosci 1998;10(05):1590-1607

139 Angiolillo DJ, Capodanno D, Goto S. Platelet thrombin receptor antagonism and atherothrombosis. Eur Heart J 2010;31(01):17-28

140 Gurbel PA, Bliden KP, Turner SE, et al. Cell-penetrating pepducin therapy targeting PAR1 in subjects with coronary artery disease. Arterioscler Thromb Vasc Biol 2016;36(01):189-197

141 Leger AJ, Covic L, Kuliopulos A. Protease-activated receptors in cardiovascular diseases. Circulation 2006;114(10):1070-1077

142 Leger AJ, Jacques SL, Badar J, et al; Circulation American Heart Association. Blocking the protease-activated receptor 1-4 heterodimer in platelet-mediated thrombosis. Circulation 2006;113 (09):1244-1254

143 Edelstein LC, Simon LM, Lindsay CR, et al. Common variants in the human platelet PAR4 thrombin receptor alter platelet function and differ by race. Blood 2014;124(23):3450-3458

144 Hamm CW, Bassand J-P, Agewall S, et al; ESC Committee for Practice Guidelines. ESC Guidelines for the management of acute coronary syndromes in patients presenting without 
persistent ST-segment elevation: The Task Force for the management of acute coronary syndromes (ACS) in patients presenting without persistent ST-segment elevation of the European Society of Cardiology (ESC). Eur Heart J 2011;32 (23):2999-3054

145 Levine GN, Bates ER, Blankenship JC, et al. ACCF/AHA/SCAI Guideline for Percutaneous Coronary Intervention: a report of the American College of Cardiology Foundation/American Heart Association Task Force on Practice Guidelines and the Society for Cardiovascular Angiography and Interventions. Circulation 2011;2011:e574-e651

146 Aradi D, Kirtane A, Bonello L, et al. Bleeding and stent thrombosis on P2Y12-inhibitors: collaborative analysis on the role of platelet reactivity for risk stratification after percutaneous coronary intervention. Eur Heart J 2015;36(27):1762-1771

147 Siller-Matula JM, Trenk D, Schrör K, et al; European Platelet Academy. How to improve the concept of individualised antiplatelet therapy with P2Y12 receptor inhibitors-is an algorithm the answer? Thromb Haemost 2015;113(01):37-52

148 Vries MJ, Van Der Meijden PE, Henskens YM, et al. Assessment of bleeding risk in patients with coronary artery disease on dual antiplatelet therapy. A systematic review. Thromb Haemost 2016;115(01):7-24

149 Collet J-P, Cuisset T, Rangé G, et al; ARCTIC Investigators. Bedside monitoring to adjust antiplatelet therapy for coronary stenting. N Engl J Med 2012;367(22):2100-2109

150 Price MJ, Angiolillo DJ, Teirstein PS, et al; Circulation American Heart Association. Platelet reactivity and cardiovascular outcomes after percutaneous coronary intervention: a time-dependent analysis of the Gauging Responsiveness with a VerifyNow P2Y12 assay: Impact on Thrombosis and Safety (GRAVITAS) trial. Circulation 2011;124(10):1132-1137

151 Trenk D, Stone GW, Gawaz M, et al. A randomized trial of prasugrel versus clopidogrel in patients with high platelet reactivity on clopidogrel after elective percutaneous coronary intervention with implantation of drug-eluting stents: results of the TRIGGER-PCI (Testing Platelet Reactivity in Patients Undergoing Elective Stent Placement on Clopidogrel to Guide Alternative Therapy With Prasugrel) study. J Am Coll Cardiol 2012;59(24):2159-2164

152 Cayla G, Cuisset T, Silvain J, et al; ANTARCTIC Investigators. Platelet function monitoring to adjust antiplatelet therapy in elderly patients stented for an acute coronary syndrome (ANTARCTIC): an open-label, blinded-endpoint, randomised controlled superiority trial. Lancet 2016;388(10055):20152022

153 Sibbing D, Aradi D, Jacobshagen C, et al. Guided de-escalation of antiplatelet treatment in patients with acute coronary syndrome undergoing percutaneous coronary intervention (TROPICALACS): a randomised, openlabel, multicentre trial; TROPICALACS Investigators. Lancet 2017;390(10104):1747-1757

154 Aradi D, Komócsi A, Price MJ, et al; Tailored Antiplatelet Treatment Study Collaboration. Efficacy and safety of intensified antiplatelet therapy on the basis of platelet reactivity testing in patients after percutaneous coronary intervention: systematic review and metaanalysis. Int J Cardiol 2013;167(05):2140-2148

155 Reny J-L, Fontana P, Hochholzer W, et al. Vascular risk levels affect the predictive value of platelet reactivity for the occurrence of MACE in patients on clopidogrel. Systematic review and meta-analysis of individual patient data. Thromb Haemost 2016; 115(04):844-855

156 Harrison P. Advances in the monitoring of anti-P2Y12 therapy. Platelets 2012;23(07):510-525

157 Hendriks JM, de Wit R, Crijns HJ, et al. Nurse-led care vs. usual care for patients with atrial fibrillation: results of a randomized trial of integrated chronic care vs. routine clinical care in ambulatory patients with atrial fibrillation. Eur Heart J 2012; 33(21):2692-2699
158 Kirchhof P, Benussi S, Kotecha D, et al. 2016 ESC Guidelines for the management of atrial fibrillation developed in collaboration with EACTS. Europace 2016;18(11):1609-1678

159 January CT, Wann LS, Alpert JS, et al. AHA/ACC/HRS guideline for the management of patients with atrial fibrillation: a report of the American College of Cardiology/American Heart Association Task Force on practice guidelines and the Heart Rhythm Society. Circulation 2014;2014:e199-e267

160 Chao T-F, Liu C-J, Wang K-L, et al. Should atrial fibrillation patients with 1 additional risk factor of the CHA2DS2-VASc score (beyond sex) receive oral anticoagulation? J Am Coll Cardiol 2015;65(07):635-642

161 Coleman Cl, Antz M, Bowrin K, et al. Real-world evidence of stroke prevention in patients with nonvalvular atrial fibrillation in the United States: the REVISIT-US study. Curr Med Res Opin 2016;32(12):2047-2053

162 Vanassche T, Lauw MN, Eikelboom JW, et al. Risk of ischaemic stroke according to pattern of atrial fibrillation: analysis of 6563 aspirin-treated patients in ACTIVE-A and AVERROES. Eur Heart J 2015;36(05):281-7a

163 Hijazi Z, Lindbäck J, Alexander JH, et al; ARISTOTLE and STABILITY Investigators. The ABC (age, biomarkers, clinical history) stroke risk score: a biomarker-based risk score for predicting stroke in atrial fibrillation. Eur Heart J 2016;37(20):1582-1590

164 Spronk HM, De Jong AM, Verheule S, et al. Hypercoagulability causes atrial fibrosis and promotes atrial fibrillation. Eur Heart J 2017;38(01):38-50

165 Hobbelt AH, Spronk HM, Crijns HJGM, Ten Cate H, Rienstra M, Van Gelder IC. Prethrombotic state in young very low-risk patients with atrial fibrillation. J Am Coll Cardiol 2017;69(15): 1990-1992

166 Dinh T, Baur LH, Pisters R, et al; TIARA Investigators. Aspirin versus vitamin $\mathrm{K}$ antagonist treatment guided by transoesophageal echocardiography in patients with atrial fibrillation: a pilot study. Heart 2014;100(07):563-568

167 Lupercio F, Carlos Ruiz J, Briceno DF, et al. Left atrial appendage morphology assessment for risk stratification of embolic stroke in patients with atrial fibrillation: A meta-analysis. Heart Rhythm 2016;13(07):1402-1409

168 Patel MR, Mahaffey KW, Garg J, et al; ROCKET AF Investigators. Rivaroxaban versus warfarin in nonvalvular atrial fibrillation. N Engl J Med 2011;365(10):883-891

169 Agnelli G, Büller HR, Cohen A, et al; AMPLIFY Investigators. Oral apixaban for the treatment of acute venous thromboembolism. N Engl J Med 2013;369(09):799-808

170 Büller HR, Décousus H, Grosso MA, et al; Hokusai-VTE Investigators. Edoxaban versus warfarin for the treatment of symptomatic venous thromboembolism. N Engl J Med 2013;369(15): 1406-1415

171 Heidbuchel H, Berti D, Campos M, et al. Implementation of nonvitamin $\mathrm{K}$ antagonist oral anticoagulants in daily practice: the need for comprehensive education for professionals and patients. Thromb J 2015;13:22

172 Patel R. Effective management of venous thromboembolism in the community: non-vitamin $\mathrm{K}$ antagonist oral anticoagulants. Int J Gen Med 2016;9:107-115

173 Sandén P, Renlund H, Svensson PJ, Själander A. Warfarin treatment complications do not correlate to cTTR when above 70 . Thromb Res 2015;136(06):1185-1189

174 Vanassche T, Hirsh J, Eikelboom JW, Ginsberg JS. Organ-specific bleeding patterns of anticoagulant therapy: lessons from clinical trials. Thromb Haemost 2014;112(05):918-923

175 Martinelli I, Lensing AW, Middeldorp S, et al. Recurrent venous thromboembolism and abnormal uterine bleeding with anticoagulant and hormone therapy use. Blood 2016;127(11): 1417-1425

176 Ansell J, Hirsh J, Hylek E, et al. Pharmacology and management of the vitamin K antagonists: American College of Chest Physicians 
Evidence-Based Clinical Practice Guidelines (8th Edition). Chest 2008;133:160S-198S

177 Ząbczyk M, Majewski J, Karkowski G, Malinowski KP, Undas A. Vitamin K antagonists favourably modulate fibrin clot properties in patients with atrial fibrillation as early as after 3days of treatment: relation to coagulation factors and thrombin generation. Thromb Res 2015;136(04):832-838

178 Dale B, Eikelboom JW, Weitz JI, et al. Dabigatran attenuates thrombin generation to a lesser extent than warfarin: could this explain their differential effects on intracranial hemorrhage and myocardial infarction? J Thromb Thrombolysis 2013;35(02): 295-301

179 Fisher MJ. Brain regulation of thrombosis and hemostasis: from theory to practice. Stroke 2013;44:3275-3285

180 De Crem N, Peerlinck K, Vanassche T, et al. Abnormal uterine bleeding in VTE patients treated with rivaroxaban compared to vitamin K antagonists. Thromb Res 2015;136(04):749-753

181 Desai J, Kolb JM, Weitz JI, Aisenberg J. Gastrointestinal bleeding with the new oral anticoagulants-defining the issues and the management strategies. Thromb Haemost 2013;110(02): 205-212

182 Aird WC. Vascular bed-specific thrombosis. J Thromb Haemost 2007;5(Suppl 1):283-291

183 Pernod G, Albaladejo P, Godier A, et al; Working Group on Perioperative Haemostasis. Management of major bleeding complications and emergency surgery in patients on longterm treatment with direct oral anticoagulants, thrombin or factor-Xa inhibitors: proposals of the working group on perioperative haemostasis (GIHP) - March 2013. Arch Cardiovasc Dis 2013;106(6-7):382-393

184 Levy JH, Ageno W, Chan NC, Crowther M, Verhamme P, Weitz JI; Subcommittee on Control of Anticoagulation. When and how to use antidotes for the reversal of direct oral anticoagulants: guidance from the SSC of the ISTH. J Thromb Haemost 2016; 14(03):623-627

185 Weitz JI, Eikelboom JW. Urgent need to measure effects of direct oral anticoagulants. Circulation 2016;134:186-188

186 Douxfils J, Mani H, Minet V, et al. Non-VKA oral anticoagulants: accurate measurement of plasma drug concentrations. BioMed Res Int 2015;2015(15):345138

187 Cuker A, Siegal DM, Crowther MA, Garcia DA. Laboratory measurement of the anticoagulant activity of the non-vitamin K oral anticoagulants. J Am Coll Cardiol 2014;64(11):1128-1139

188 Gosselin RC, Adcock D, Hawes EM, Francart SJ, Grant RP, Moll S. Evaluating the use of commercial drug-specific calibrators for determining PT and APTT reagent sensitivity to dabigatran and rivaroxaban. Thromb Haemost 2015;113(01):77-84

189 Seiffge DJ, Traenka C, Polymeris A, et al. Feasibility of rapid measurement of Rivaroxaban plasma levels in patients with acute stroke. J Thromb Thrombolysis 2017;43(01): 112-116

190 Bluecher A, Meyer Dos Santos S, Ferreirós N, et al. Microfluidic coagulation assay for monitoring anticoagulant therapy in acute stroke patients. Thromb Haemost 2017;117(03):519-528

191 Schulman S, Kearon C, Kakkar AK, et al; RE-COVER Study Group. Dabigatran versus warfarin in the treatment of acute venous thromboembolism. N Engl J Med 2009;361(24): 2342-2352

192 Büller HR, Prins MH, Lensin AW, et al; EINSTEIN-PE Investigators. Oral rivaroxaban for the treatment of symptomatic pulmonary embolism. N Engl J Med 2012;366(14):1287-1297

193 Bauersachs R, Berkowitz SD, Brenner B, et al; EINSTEIN Investigators. Oral rivaroxaban for symptomatic venous thromboembolism. N Engl J Med 2010;363(26):2499-2510

194 Granger CB, Alexander JH, McMurray JJV, et al; ARISTOTLE Committees and Investigators. Apixaban versus warfarin in patients with atrial fibrillation. N Engl J Med 2011;365(11): 981-992
195 Giugliano RP, Ruff CT, Braunwald E, et al; ENGAGE AF-TIMI 48 Investigators. Edoxaban versus warfarin in patients with atrial fibrillation. N Engl J Med 2013;369(22):2093-2104

196 Mueck W, Lensing AW, Agnelli G, Decousus H, Prandoni P, Misselwitz F. Rivaroxaban: population pharmacokinetic analyses in patients treated for acute deep-vein thrombosis and exposure simulations in patients with atrial fibrillation treated for stroke prevention. Clin Pharmacokinet 2011;50(10): 675-686

197 Girgis IG, Patel MR, Peters GR, et al. Population pharmacokinetics and pharmacodynamics of rivaroxaban in patients with nonvalvular atrial fibrillation: results from ROCKET AF. J Clin Pharmacol 2014;54(08):917-927

198 Reilly PA, Lehr T, Haertter S, et al; RE-LY Investigators. The effect of dabigatran plasma concentrations and patient characteristics on the frequency of ischemic stroke and major bleeding in atrial fibrillation patients: the RE-LY Trial (Randomized Evaluation of Long-Term Anticoagulation Therapy). J Am Coll Cardiol 2014;63 (04):321-328

199 Ruff CT, Giugliano RP, Braunwald E, et al. Association between edoxaban dose, concentration, anti-Factor Xa activity, and outcomes: an analysis of data from the randomised, double-blind ENGAGE AF-TIMI 48 trial. Lancet 2015;385(9984):2288-2295

200 Chan NC, Coppens M, Hirsh J, et al. Real-world variability in dabigatran levels in patients with atrial fibrillation. J Thromb Haemost 2015;13(03):353-359

201 Douxfils J, Chatelain B, Dogné J-M, Mullier F. Real-world variability in dabigatran levels in patients with atrial fibrillation: comment. J Thromb Haemost 2015;13(06):1166-1168

202 Douxfils J, Lessire S, Dincq A-S, et al. Estimation of dabigatran plasma concentrations in the perioperative setting. An ex vivo study using dedicated coagulation assays. Thromb Haemost 2015;113(04):862-869

203 Skeppholm M, Al-Aieshy F, Berndtsson M, et al. Clinical evaluation of laboratory methods to monitor apixaban treatment in patients with atrial fibrillation. Thromb Res 2015;136(01):148-153

204 Al-Aieshy F, Malmström RE, Antovic J, et al. Clinical evaluation of laboratory methods to monitor exposure of rivaroxaban at trough and peak in patients with atrial fibrillation. Eur J Clin Pharmacol 2016;72(06):671-679

205 Skeppholm M, Hjemdahl P, Antovic JP, et al. On the monitoring of dabigatran treatment in "real life" patients with atrial fibrillation. Thromb Res 2014;134(04):783-789

206 Mueck W, Stampfuss J, Kubitza D, Becka M. Clinical pharmacokinetic and pharmacodynamic profile of rivaroxaban. Clin Pharmacokinet 2014;53(01):1-16

207 Weitz JI, Connolly SJ, Patel I, et al. Randomised, parallel-group, multicentre, multinational phase 2 study comparing edoxaban, an oral factor Xa inhibitor, with warfarin for stroke prevention in patients with atrial fibrillation. Thromb Haemost 2010;104(03): 633-641

208 Verhamme P, Wells PS, Segers A, et al. Dose reduction of edoxaban preserves efficacy and safety for the treatment of venous thromboembolism. An analysis of the randomised, double-blind HOKUSAI VTE trial. Thromb Haemost 2016;116(04): 747-753

209 Hylek EM, Held C, Alexander JH, et al. Major bleeding in patients with atrial fibrillation receiving apixaban or warfarin: The ARISTOTLE Trial (Apixaban for Reduction in Stroke and Other Thromboembolic Events in Atrial Fibrillation): Predictors, Characteristics, and Clinical Outcomes. J Am Coll Cardiol 2014;63 (20):2141-2147

210 Piccini JP, Garg J, Patel MR, et al; ROCKET AF Investigators. Management of major bleeding events in patients treated with rivaroxaban vs. warfarin: results from the ROCKET AF trial. Eur Heart J 2014;35(28):1873-1880

211 Ruff CT, Giugliano RP, Braunwald E, et al. Comparison of the efficacy and safety of new oral anticoagulants with warfarin in 
patients with atrial fibrillation: a meta-analysis of randomised trials. Lancet 2014;383(9921):955-962

212 van der Hulle T, Kooiman J, den Exter PL, Dekkers OM, Klok FA, Huisman MV. Effectiveness and safety of novel oral anticoagulants as compared with vitamin $\mathrm{K}$ antagonists in the treatment of acute symptomatic venous thromboembolism: a systematic review and meta-analysis. J Thromb Haemost 2014;12(03):320-328

213 Baglin TP, Langdown J, Frasson R, Huntington JA. Discovery and characterization of an antibody directed against exosite I of thrombin. J Thromb Haemost 2016;14(01):137-142

214 Pan J, Liu T, Kim J-Y, et al. Enhanced efficacy of recombinant FVIII in noncovalent complex with PEGylated liposome in hemophilia A mice. Blood 2009;114(13):2802-2811

215 Buyue Y, Whinna HC, Sheehan JP. The heparin-binding exosite of factor IXa is a critical regulator of plasma thrombin generation and venous thrombosis. Blood 2008;112(08):3234-3241

216 Monroe DM, Hoffman M. A mouse bleeding model to study oral anticoagulants. Thromb Res 2014;133(Suppl 1):S6-S8

217 Hechler B, Gachet C. Comparison of two murine models of thrombosis induced by atherosclerotic plaque injury. Thromb Haemost 2011;105(Suppl 1):S3-S12

218 Jolly SS, James S, Džavík V, et al; Circulation American Heart Association. Thrombus aspiration in ST-segment-elevation myocardial infarction: an individual patient meta-analysis: Thrombectomy Trialists Collaboration. Circulation 2017;135(02):143-152

219 Berkhemer OA, Fransen PS, Beumer D, et al; MR CLEAN Investigators. A randomized trial of intraarterial treatment for acute ischemic stroke. N Engl J Med 2015;372(01):11-20

220 van Es AC, Autar AS, Emmer BJ, Lycklama À Nijeholt GJ, van der Kallen BF, van Beusekom HM. Imaging stent-thrombus interaction in mechanical thrombectomy. Neurology 2017;88(02):216-217

221 Griffin JH, Mosnier LO, Fernández JA, Zlokovic BV; Arterioscler Thromb Vasc Biol American Heart Association. 2016 Scientific Sessions Sol Sherry Distinguished Lecturer in Thrombosis: Thrombotic Stroke: Neuroprotective therapy by recombinantactivated protein C. Arterioscler Thromb Vasc Biol 2016;36(11): 2143-2151

222 Griffin JH, Zlokovic BV, Mosnier LO. Activated protein C: biased for translation. Blood 2015;125(19):2898-2907

223 Mosnier LO, Zlokovic BV, Griffin JH. Cytoprotective-selective activated protein $C$ therapy for ischaemic stroke. Thromb Haemost 2014;112(05):883-892

224 Burnier L, Mosnier LO. Novel mechanisms for activated protein C cytoprotective activities involving noncanonical activation of protease-activated receptor 3. Blood 2013;122(05):807-816

225 Wardlaw JM, Murray V, Berge E, del Zoppo GJ. Thrombolysis for acute ischaemic stroke. Cochrane Database Syst Rev 2014;7(07): CD000213

226 Zinkstok SM, Roos YB; ARTIS Investigators. Early administration of aspirin in patients treated with alteplase for acute ischaemic stroke: a randomised controlled trial. Lancet 2012;380(9843):731-737
227 Goyal M, Demchuk AM, Menon BK, et al; ESCAPE Trial Investigators. Randomized assessment of rapid endovascular treatment of ischemic stroke. N Engl J Med 2015;372(11):1019-1030

228 Jovin TG, Chamorro A, Cobo E, et al; REVASCAT Trial Investigators. Thrombectomy within 8 hours after symptom onset in ischemic stroke. N Engl J Med 2015;372(24):2296-2306

229 Saver JL, Goyal M, Bonafe A, et al; SWIFT PRIME Investigators. Stent-retriever thrombectomy after intravenous t-PA vs. t-PA alone in stroke. N Engl J Med 2015;372(24):2285-2295

230 Goyal M, Menon BK, van Zwam WH, et al; HERMES Collaborators. Endovascular thrombectomy after large-vessel ischaemic stroke: a meta-analysis of individual patient data from five randomised trials. Lancet 2016;387(10029):1723-1731

231 Campbell BCV, Donnan GA, Lees KR, et al. Endovascular stent thrombectomy: the new standard of care for large vessel ischaemic stroke. Lancet Neurol 2015;14(08):846-854

232 Powers WJ, Derdeyn CP, Biller J, et al. American Heart Association/American Stroke Association Focused Update of the 2013 Guidelines for the Early Management of Patients With Acute Ischemic Stroke Regarding Endovascular Treatment: A Guideline for Healthcare Professionals From the American Heart Association/American Stroke Association. Stroke 2015;2015: 3020-3035

233 Wahlgren N, Moreira T, Michel P, et al; ESO-KSU, ESO, ESMINT, ESNR and EAN. Mechanical thrombectomy in acute ischemic stroke: Consensus statement by ESO-Karolinska Stroke Update 2014/2015, supported by ESO, ESMINT, ESNR and EAN. Int J Stroke 2016;11(01):134-147

234 Santos EM, Marquering HA, Blanken den MD, et al. Thrombus permeability is associated with improved functional outcome and recanalization in patients with ischemic stroke. Stroke 2016; 47:732-741

235 Bai J, Lyden PD. Revisiting cerebral postischemic reperfusion injury: new insights in understanding reperfusion failure, hemorrhage, and edema. Int J Stroke 2015;10(02):143-152

236 Jin X, Liu J, Liu W. Early ischemic blood brain barrier damage: a potential indicator for hemorrhagic transformation following tissue plasminogen activator (tPA) thrombolysis? Curr Neurovasc Res 2014;11(03):254-262

237 Denorme F, Langhauser F, Desender L, et al. ADAMTS13mediated thrombolysis of t-PA-resistant occlusions in ischemic stroke in mice. Blood 2016;127(19):2337-2345

238 Denorme F, De Meyer SF. The VWF-GPIb axis in ischaemic stroke: lessons from animal models. Thromb Haemost 2016;116(04): 597-604

239 Wyseure T, Declerck PJ. Novel or expanding current targets in fibrinolysis. Drug Discov Today 2014;19(09):1476-1482

240 Wyseure T, Rubio M, Denorme F, et al. Innovative thrombolytic strategy using a heterodimer diabody against TAFI and PAI-1 in mouse models of thrombosis and stroke. Blood 2015;125(08): 1325-1332 